Cite this: Phys. Chem. Chem. Phys., 2012, 14, 12773-12793

wwW.rsc.org/pccp

PAPER

\title{
Kinetics of $\alpha$ hydrogen abstractions from thiols, sulfides and thiocarbonyl compounds $\dagger$
}

\author{
Aäron G. Vandeputte, Maarten K. Sabbe, Marie-Françoise Reyniers* and \\ Guy B. Marin
}

Received 6th April 2012, Accepted 29th June 2012

DOI: $10.1039 / \mathrm{c} 2 \mathrm{cp} 41114 \mathrm{~h}$

Hydrogen abstraction reactions involving organosulfur compounds play an important role in many industrial, biological and atmospheric processes. Despite their chemical relevance, little is known about their kinetics. In this work a group additivity model is developed that allows predicting the Arrhenius parameters for abstraction reactions of $\alpha$ hydrogen atoms from thiols, alkyl sulfides, alkyl disulfides and thiocarbonyl compounds by carbon-centered radicals at temperatures ranging from 300 to $1500 \mathrm{~K}$. Rate coefficients for 102 hydrogen abstractions were obtained using conventional transition state theory within the high-pressure limit. Electronic barriers were calculated using the CBS-QB3 method and the rate coefficients were corrected for tunneling and hindered rotation about the transitional bond. Group additivity values for 46 groups are determined. To account for resonance and hyperconjugative stabilization in the transition state, 8 resonance corrections were fitted to a set of 32 reactions. The developed group additivity scheme was validated using a test set containing an additional 30 reactions. The group additivity scheme succeeds in reproducing the rate coefficients on average within a factor of 2.4 at $300 \mathrm{~K}$ and 1.4 at $1000 \mathrm{~K}$. Mean absolute deviations of the Arrhenius parameters amount to, respectively, $2.5 \mathrm{~kJ} \mathrm{~mol}^{-1}$ for $E_{\mathrm{a}}$ and 0.13 for $\log A$, both at 300 and $1000 \mathrm{~K}$. This work hence illustrates that the recently developed group additivity methods for Arrhenius parameters extrapolate successfully to hetero-element containing compounds.

\section{Introduction}

Despite the fact that sulfur compounds play an important role in many atmospheric, biological and chemical processes, ${ }^{1-3}$ large parts of their chemistry remain largely unknown. Recent studies have shown that reactions involving organosulfur compounds occur via complex radical chemistries making it hard to derive a reaction mechanism and extract reliable rate coefficients from experimental data only. ${ }^{4-10}$ Often, the decomposition of small organosulfur compounds is accompanied with the formation of large chain polysulfides, ${ }^{11}$ which can result in deficient sulfur balances if those compounds remain undetected. Extended reaction networks accounting for the formation of heavier sulfur compounds can help in identifying unknown species. Recently, automatic reaction network generating tools

Laboratorium voor Chemische Technologie, Ghent University,

Krijgslaan 281 S5, B-9000 Gent, Belgium.

E-mail: MarieFrancoise.Reyniers@Ugent.be; Fax: + 32 92644999;

Tel: +3292649655

$\dagger$ Electronic supplementary information (ESI) available: Rate coefficients, tunneling coefficients and symmetry numbers for all reactions presented in this work and B3LYP/6-311G(2d,d,p) geometries for all reactants, products and transition states. Guidelines for the determination of the symmetry numbers are provided. See DOI: 10.1039 / c2cp41114h have become available that allow description of complex radical chemistries at the molecular level. ${ }^{12}$ Radical reaction networks can easily contain up to thousands of reactions and for each reaction reliable rate coefficients need to be at hand. Since hydrogen abstraction reactions involving organosulfur compounds play an important role in the free-radical chemistry of many processes such as polymerization, combustion, pyrolysis and steam cracking of hydrocarbons, ${ }^{8,13}$ kinetic data for this reaction family are indispensable for reaction network generation.

Despite the increase in computational performance, ab initio methods still remain too demanding to calculate all the required rate coefficients, in particular for the larger species in the network. To keep the effort tractable, kinetic parameters are frequently obtained using kinetic correlations. ${ }^{14-20}$ The most popular correlation is without doubt the Bell-EvansPolanyi relationship, which correlates the activation energy for reactions within the same reaction family to the reaction enthalpy. ${ }^{14,15}$ Many extensions to the Bell-Evans-Polanyi (BEP) relationship have been proposed in order to increase its accuracy. However, the introduction of additional parameters in the relationship limits its applicability in practice. Two such extended models are the intersecting parabolas (IP) method $^{16}$ and the Blowers and Masel model. ${ }^{17}$ The major limitation of these BEP-type methods is that only activation energies can be estimated. 
Pre-exponential factors hence have to be obtained from other sources.

Alternative methods that can model both Arrhenius parameters rely on the additivity ${ }^{21}$ of enthalpy and entropy in the transition state or on the reaction class approach. ${ }^{22-33}$ Sumathi et al. ${ }^{27,28}$ proposed a method to obtain accurate kinetic data for hydrogen abstraction reactions using supergroups that encompass the reactive moiety of the transition state structure. The major advantage of these supergroups is that they can account for non-atom-centered contributions, i.e. contributions originating from interactions between non-adjacent groups, for example cis/trans or gauche interactions. Supergroups are larger than the commonly used Benson-like groups, resulting in the total amount of possible supergroups outnumbering the amount of their Benson analogues. Truong et al. ${ }^{29}$ used reaction class transition state theory to predict rate coefficients for hydrogen abstraction reactions between methyl and alkanes ${ }^{30}$ and between hydrogen and alcohols. ${ }^{32,33}$ In this approach the rate coefficient of a target reaction can be calculated by multiplying the rate coefficient of a reference reaction with a set of four correction factors accounting for effects of symmetry, tunneling, partition function and potential energy. In this work, the group additivity (GA) method as proposed by Saeys et al. ${ }^{25}$ and further extended by Sabbe et al. ${ }^{26}$ is used to model the kinetics of hydrogen abstractions involving organosulfur compounds. This method makes use of the additivity of enthalpy and entropy for reactants and transition state. This allows us to obtain the kinetic parameters as perturbations to a reference reaction. The group additivity values (GAVs) can be obtained from high-level quantum chemical calculations. The method has proven to be successful in predicting rate coefficients of addition reactions and hydrogen abstractions for hydrocarbons ${ }^{26,34}$ and $\mathrm{H}_{2}$ additions, 1,2-hydrogen shifts and cyclization reactions for silicon-containing compounds. ${ }^{35-37}$

The aim of this work is to extend the previously developed additivity schemes for Arrhenius parameters of hydrogen abstraction reactions between hydrocarbons to sulfur containing compounds. $^{25,26}$ To this end, Arrhenius parameters are obtained from high-level quantum chemical calculations. Although hydrogen abstraction reactions have been extensively studied in literature, ${ }^{27,28,38-40}$ kinetic data for abstractions involving sulfur compounds are still scarce and only very limited attention has been given to the influence of neighboring $\mathrm{S}$ and $\mathrm{C}=\mathrm{S}$ groups on the kinetics of a $\mathrm{C}-\mathrm{H}-\mathrm{C}$ type of hydrogen abstraction reactions.

Benchmark studies have assessed the influence of the level of theory, tunneling and hindered rotor corrections on the reaction kinetics of this reaction family. Coote ${ }^{41}$ studied geometries, barriers and reaction enthalpies for hydrogen abstraction reactions involving heteroatom containing hydrocarbons and showed that high-level composite procedures were in good agreement with experimental data. Barrier heights for an elaborate set of hydrogen abstractions were studied in the work of Zheng et $a l .^{42,43}$ In a recent study we assessed the influence of the level of theory, tunneling and 1-D hindered rotor (1-D HR) treatment for hydrogen abstractions involving hydrocarbons. ${ }^{40}$ It was observed that the best agreement with experimental data for a large set of hydrogen abstractions was obtained using the CBS-QB3 method within the 1D-HR treatment of the internal rotation about the transition state bond and corrected for tunneling effects according to the Eckart scheme. ${ }^{44}$

In this work, the effect of an $\alpha \mathrm{S}$-atom or a thiocarbonyl group on the rate coefficients of hydrogen abstraction reactions is investigated. Due to their importance in combustion, pyrolysis and polymerization processes, the applicability of group additivity schemes for Arrhenius parameters is explored for this reaction family. The various steps that need consideration in order to extrapolate currently developed group additivity schemes to reactions involving hetero-elements are discussed. Arrhenius parameters for a set of 102 reactions are calculated using the CBS-QB3 composite method corrected for the 1-D hindered rotation about the transitional bond. Tunneling contributions were calculated according to the Eckart scheme. ${ }^{44} 46$ group additivity values are determined both for activation energies and pre-exponential factors. Eight corrections accounting for resonance in the transition state were determined by regression of group additively modeled Arrhenius parameters to kinetic data calculated for a set of 32 reactions. The accuracy of the group additivity method is assessed by comparison of CBS-QB3 data with group additively modeled data for a test set containing 30 additional reactions.

\section{Computational methods}

\subsection{Rate coefficients}

The rate coefficients presented in this work were calculated using classical transition state theory:

$$
k_{\infty}(T)=\kappa_{\text {Eckart }}(T) \frac{k_{\mathrm{B}} T}{h} \frac{q_{\ddagger}}{q_{\mathrm{A}} q_{\mathrm{B}}} \mathrm{e}^{-\frac{\Delta E(0 \mathrm{~K})}{R T}}
$$

In eqn (1) $q$ represents the total partition function per unit volume, $\Delta E(0 \mathrm{~K})$ the electronic zero-point corrected reaction barrier and $\kappa_{\text {Eckart }}(T)$ the Eckart transmission coefficient accounting for quantum mechanical effects. The electronic barrier at $0 \mathrm{~K}$ is determined with the CBS-QB3 complete basis set method of Montgomery et al. ${ }^{45}$ which is implemented in the Gaussian 03 computational package. ${ }^{46}$ Partition functions $q$ are calculated at the $\mathrm{B} 3 \mathrm{LYP} / 6-311 \mathrm{G}(2 \mathrm{~d}, \mathrm{~d}, \mathrm{p})$ level using a default scaling factor of 0.99. B3LYP geometries of all species considered in this work can be found in the ESI. $\dagger$ The rotation about the transitional bond is treated as a one-dimensional hindered internal rotor. ${ }^{47,48}$ In case the barrier for rotation is lower than $1 \mathrm{~kJ} \mathrm{~mol}^{-1}$, the rotation is treated as a free rotor. Arrhenius parameters $\left(E_{\mathrm{a}}\right.$ and $\log A$ ) were obtained by fitting to $a b$ initio rate coefficients in the temperature range $T-$ $100 \mathrm{~K}$ to $T+100 \mathrm{~K}$, with $T$ the temperature of interest. Rate coefficients for all reactions considered in this study at temperatures ranging from $300-1500 \mathrm{~K}$ are presented in Tables S2-S5 of ESI. $\dagger$

In this study, the accuracy of the GA method is assessed by comparing ab initio calculated rate coefficients and rate coefficients estimated by the group additivity method. As a measure of the deviation between both values we opted to define a factor $\rho$ according to eqn (2).

$$
\begin{cases}\rho=\frac{k_{\mathrm{AI}}}{k_{\mathrm{GA}}} & k_{\mathrm{AI}}>k_{\mathrm{GA}} \\ \rho=\frac{k_{\mathrm{GA}}}{k_{\mathrm{AI}}} & k_{\mathrm{GA}}>k_{\mathrm{AI}}\end{cases}
$$


The factor $\rho$ is a value larger than 1 and gives a proper indication of the relative deviation between both rate coefficients. Furthermore, it permits us to calculate a significant arithmetic mean value for a set of reactions, $\langle\rho\rangle$.

\subsection{Group additivity method}

Using the group additive model, the rate coefficient can be obtained as

$$
k=\kappa n_{\mathrm{e}} k_{\mathrm{GA}}=\kappa n_{\mathrm{e}} \tilde{A} \mathrm{e}^{-\frac{E_{\mathrm{a}}}{R T}}
$$

with $\kappa$ the tunneling coefficient, $n_{\mathrm{e}}$ the reaction path degeneracy (see eqn (7)), $\tilde{A}$ the single-event pre-exponential factor and $E_{\mathrm{a}}$ the activation energy. The group additivity method for Arrhenius parameters presented in this work is an extension of the work of Sabbe $e a^{26} .^{26}$ for hydrogen abstraction reactions involving hydrocarbons. By applying Benson's group additivity method for transition states, the Arrhenius parameters of a target reaction can be calculated by adding perturbations to the Arrhenius parameters of a reference reaction. ${ }^{26}$ The added perturbations relate to structural differences between the transition state of the target reaction and that of the reference reaction. Besides hydrogen abstraction reactions, this additivity scheme has also proven to yield accurate kinetic data for addition reactions between hydrocarbons. ${ }^{24,34,49}$ As the details of the method have been presented elsewhere, ${ }^{25,26}$ only a brief overview is given here.

Within Benson's method a group is defined as a polyvalent atom together with all of its ligands. Groups are hence characterized as $\mathrm{X}-(\mathrm{A})_{i}(\mathrm{~B})_{j}(\mathrm{C})_{k}(\mathrm{D})_{l}$ with $\mathrm{X}$ the central atom surrounded by $i \mathrm{~A}$ atoms, $j \mathrm{~B}$ atoms, $k \mathrm{C}$ atoms and $l \mathrm{D}$ atoms. In this work distinction is made between different carbon- and sulfur-centered groups: $\mathrm{C}$ and $\mathrm{S}$ are used to indicate, respectively, a saturated carbon and a sulfur atom, $C_{d}$ and $C_{t}$ represent, respectively, a double and a triple bonded carbon atom, $\mathrm{C}_{\mathrm{B}}$ and $\mathrm{C}_{\mathrm{T}}$ indicate a carbon atom in a benzene and a thiophene ring, respectively, and CS denotes a thiocarbonyl group.

A schematic representation of a transition state for a $\mathrm{C}-\mathrm{H}-\mathrm{C}$ type of hydrogen abstraction is shown in Fig. 1. In order to extend Benson's additivity scheme to transition states for hydrogen abstraction reactions, two additional groups are introduced, located on the two carbon atoms that exchange the hydrogen atom. These two groups are indicated by the subscripts 1 and 2: 1 for the carbon atom abstracting the hydrogen atom and 2 for the carbon atom from which a hydrogen atom is abstracted. Distinction between the abstracting and

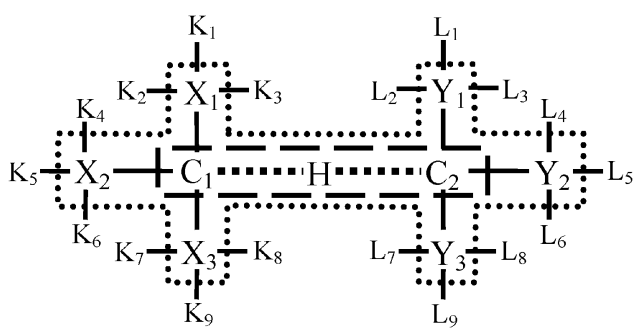

Fig. 1 Schematic representation of the transition state for abstraction of a hydrogen atom bonded to a carbon atom by a carbon-centered radical. ${ }^{24}$ The full line indicates the central atoms of the primary contributions. The dotted line indicates the central atoms of the primary and secondary contributions. the abstracted group is needed to specify the direction of the reaction. As pointed out by Sabbe et al. ${ }^{26}$ the activation energy of a target hydrogen abstraction reaction can be obtained from a truncated GA model, using:

$$
E_{\mathrm{a}}(T)=E_{\mathrm{a}, \text { ref }}(T)+\sum_{i=1}^{2} \Delta \mathrm{GAV}_{E_{\mathrm{a}}}^{\mathrm{o}}\left(C_{\mathrm{i}}\right)+\Delta E_{\mathrm{a}, \text { res }}^{\mathrm{o}}
$$

with $E_{\mathrm{a} \text {,ref }}$ the activation energy of the reference reaction, $\Delta \mathrm{GAV}^{\mathrm{o}}\left(\mathrm{C}_{i}\right)$ the group additivity values and $\Delta E_{\mathrm{a}, \text { res }}^{\mathrm{o}}$ the resonance correction factor. One of the advantages of introducing a reference reaction is that the temperature dependence of $E_{\mathrm{a}}$ is incorporated in $E_{\mathrm{a} \text {,ref }}$ leaving the $\Delta \mathrm{GAV}^{\mathrm{O}} \mathrm{s}$ almost temperature independent. In analogy with the work of Sabbe et al., ${ }^{26}$ the $\mathrm{H}$ abstraction from methane by methyl is chosen as reference reaction. The major contributions to the Arrhenius parameters are from the two groups between which the hydrogen atom is exchanged. Contributions from $\mathrm{X}$ and $\mathrm{Y}$ groups neighboring the $\mathrm{C}-\mathrm{H}-\mathrm{C}$ reactive site, i.e. secondary contributions (see Fig. 1), were found to have a minor effect on the reaction kinetics and can generally be neglected. ${ }^{25}$ Also contributions of non-nearestneighbor interactions (NNIs) were neglected in previous work since their influence on the Arrhenius parameters is small and they are only needed for reactions with severe steric hindrance.

To illustrate the applicability of a truncated GA model for hydrogen abstraction reactions involving organosulfur compounds, abstractions by methyl from the different secondary carbon atoms in butane-1-thiol were studied. This allows us to investigate the effect of a thiol group on hydrogen abstraction reactions in the $\alpha$-, $\beta$ - and $\gamma$-position of this group. Resulting transition state geometries and CBS-QB3 barriers, $\Delta E^{\ddagger}$, are presented in Fig. 2. For hydrogen abstraction from a carbon atom in the $\alpha$-, $\beta$ - and $\gamma$-position of the sulfur atom, barriers of, respectively, 39.4, 46.9 and $46.7 \mathrm{~kJ} \mathrm{~mol}^{-1}$ are obtained. These data illustrate that an adjacent sulfur atom lowers the activation energy for hydrogen abstraction by approximately $8 \mathrm{~kJ} \mathrm{~mol}^{-1}$. This lowering of the activation energy is limited to the neighboring $\mathrm{C}$-atom. The barriers obtained for hydrogen abstraction from the carbon atoms in the $\beta$ - and $\gamma$-position of the sulfur atom are in good agreement with the one obtained for hydrogen abstraction from propane, i.e. $48.3 \mathrm{~kJ} \mathrm{~mol}^{-1}$. Adjacent sulfur atoms stabilize the formed radical and transition state by the $\alpha$-effect, i.e. the sharing of the sulfur's lone electron pair with a neighboring electron deficient centre. This results in a stronger $\mathrm{C}-\mathrm{S}$ bond and a decreasing $\mathrm{C}-\mathrm{S}$ bond length. This is also illustrated in Fig. 2. In the transition states for hydrogen abstraction from carbon atoms in the $\beta$ - and $\gamma$-position of the sulfur atom, the $\mathrm{C}-\mathrm{S}$ bond length amounts to $184 \mathrm{pm}$ (which is equal to the $\mathrm{C}-\mathrm{S}$ bond length in butane-1-thiol), compared to a value of $180 \mathrm{pm}$ in the case of hydrogen abstraction from the carbon atom in the $\alpha$-position of the $\mathrm{S}$ atom.

Similar results were also obtained for hydrogen abstraction from pentanethial $\left(\mathrm{CH}_{3} \mathrm{CH}_{2} \mathrm{CH}_{2} \mathrm{CH}_{2} \mathrm{C}(=\mathrm{S}) \mathrm{H}\right)$. CBS-QB3 barriers, $\Delta E^{\ddagger}$, for abstraction of a hydrogen in the $\alpha$-, $\beta$ - and $\gamma$-position of the thiocarbonyl group by methyl amount to 24.7, 46.9 and $46.7 \mathrm{~kJ} \mathrm{~mol}^{-1}$, respectively. In analogy with thiol groups, thiocarbonyl groups only influence the abstraction reactions of hydrogen atoms in the $\alpha$-position. Hence, an extension of the GA model for $\mathrm{C}-\mathrm{H}-\mathrm{C}$ type hydrogen abstraction reactions 

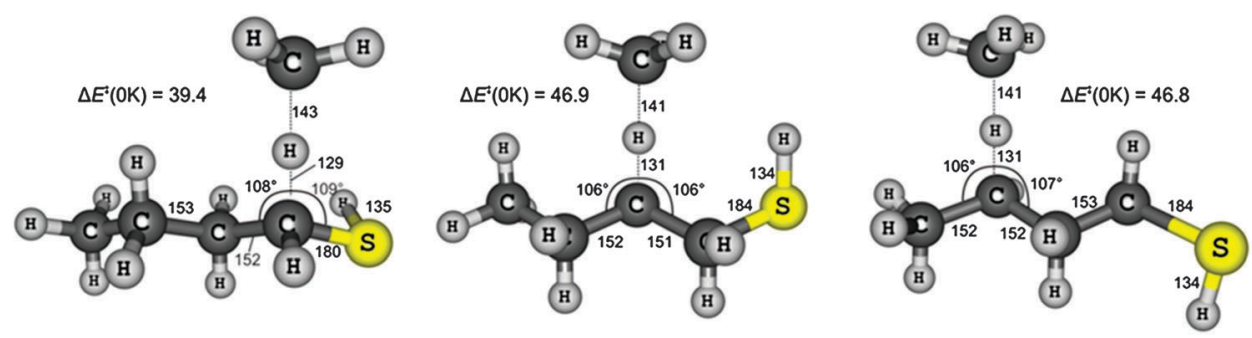

Fig. 2 B3LYP/6-311G(2d,d,p) transition state geometries for hydrogen abstractions from butane-1-thiol by methyl. Transition states for abstraction from the carbon atom in $\alpha, \beta$ and $\gamma$ positions of the thiol group are shown. CBS-QB3 energy barriers $\Delta E^{\ddagger}(0 \mathrm{~K})$ are indicated in $\mathrm{kJ}^{\mathrm{mol}}{ }^{-1}$.

from hydrocarbons to organosulfur compounds only requires additional additivity values for hydrogen abstractions of carbon atoms having adjacent thiol and thiocarbonyl groups. In Section 3.3.2, the limited influence of secondary contributions and NNIs on the Arrhenius parameters will be further illustrated.

$\Delta \mathrm{GAV}_{E_{\mathrm{a}}}^{\mathrm{o}}\left(\mathrm{C}_{1}\right)$ is determined as the difference between the activation energy of the hydrogen abstraction by a given radical from methane and the activation energy of the reference reaction, i.e. the hydrogen abstraction by methyl from methane. $\Delta \mathrm{GAV}^{\mathrm{O}}\left(\mathrm{C}_{1}\right)$ hence accounts for the influence of resonance and hyperconjugation resulting from groups centered on $C_{1}$. Similarly, $\Delta \operatorname{GAV}^{\circ}\left(C_{2}\right)$ includes the influence of resonance and hyperconjugation due to groups centered on $C_{2}$. Therefore, the term $\Delta E_{\mathrm{a}, \text { res }}^{\mathrm{o}}$ in eqn (4) is a correction term that accounts for additional resonance and hyperconjugative stabilization in the transition state due to the simultaneous presence of ligands on the $\mathrm{C}_{1}$ and $\mathrm{C}_{2}$ groups. To capture these cross resonance and/or hyperconjugative stabilization effects in the transition state, Sabbe et al. ${ }^{26}$ have introduced 4 corrections that allow us to account for every occurrence of a $\pi=-\pi=, \pi=-\pi \equiv, \pi \equiv-\pi \equiv, \pi-\sigma_{\beta \mathrm{C}-\mathrm{H}}$ and $\sigma_{\beta \mathrm{C}-\mathrm{H}^{-}}-\sigma_{\beta \mathrm{C}-\mathrm{H}}$ interaction in the transition state for hydrogen transfer involving hydrocarbons. In this work, additional corrections are presented for cross-interactions involving $\alpha$-sulfur atoms and thiocarbonyl groups.

The need for resonance correction terms is illustrated with an example, i.e. the hydrogen abstraction reaction from the $\mathrm{C}$ atom in methanethiol $\left(\mathrm{CH}_{3} \mathrm{SH}\right)$ by the methylenethiol radical $\left(\mathrm{C}^{\bullet} \mathrm{H}_{2} \mathrm{SH}\right)(\mathrm{R}-\mathrm{I})$.

$$
\begin{aligned}
\mathrm{C}^{\bullet} \mathrm{H}_{2} \mathrm{SH}+\mathrm{CH}_{3} \mathrm{SH} & \rightarrow \mathrm{CH}_{3} \mathrm{SH}+\mathrm{C}^{\bullet} \mathrm{H}_{2} \mathrm{SH} \\
\mathrm{C}^{\bullet} \mathrm{H}_{3}+\mathrm{CH}_{4} & \rightarrow \mathrm{CH}_{4}+\mathrm{C}^{\bullet} \mathrm{H}_{3} \\
\mathrm{C}^{\bullet} \mathrm{H}_{2} \mathrm{SH}+\mathrm{CH}_{4} & \rightarrow \mathrm{C}^{\bullet} \mathrm{H}_{3}+\mathrm{CH}_{3} \mathrm{SH} \\
\mathrm{C}^{\bullet} \mathrm{H}_{3}+\mathrm{CH}_{3} \mathrm{SH} & \rightarrow \mathrm{CH}_{4}+\mathrm{C}^{\bullet} \mathrm{H}_{2} \mathrm{SH}
\end{aligned}
$$

(A)

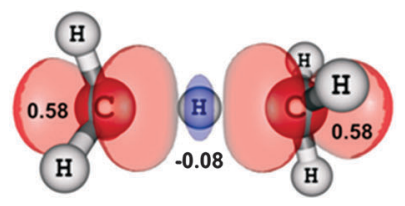

The two $\triangle \mathrm{GAV}^{\mathrm{S}} \mathrm{s}$ required to estimate the Arrhenius parameters for this reaction are $\Delta \mathrm{GAV}^{\mathrm{O}}\left(\mathrm{C}_{1}-(\mathrm{S})(\mathrm{H})_{2}\right)$ and $\Delta \mathrm{GAV}^{\mathrm{O}}\left(\mathrm{C}_{2}-(\mathrm{S})(\mathrm{H})_{2}\right)$. These two $\Delta \mathrm{GAV}^{\mathrm{o}} \mathrm{S}$ account for the influence of a sulfur ligand on the $\mathrm{C}_{1}$ and $\mathrm{C}_{2}$ groups, respectively. The $\Delta \mathrm{GAV}^{\mathrm{O}}\left(\mathrm{C}_{1}-(\mathrm{S})(\mathrm{H})_{2}\right)$ values are equal to the difference between the Arrhenius parameters obtained for the hydrogen abstraction from methane by $\mathrm{C}^{\bullet} \mathrm{H}_{2} \mathrm{SH}((\mathrm{R}-\mathrm{III}))$ and those of the reference reaction (R-II). Similarly, the $\Delta \mathrm{GAV}^{\mathrm{O}}\left(\mathrm{C}_{2}-(\mathrm{S})(\mathrm{H})_{2}\right)$ values are equal to the difference between the Arrhenius parameters of reaction $(\mathrm{R}-\mathrm{IV})$, which is the reverse of $(\mathrm{R}-\mathrm{III})$, and those of the reference reaction $(\mathrm{R}-\mathrm{II})$.

The spin density plots for the transition states of the reference reaction $(\mathrm{R}-\mathrm{II})$, reactions (R-III), (R-IV) and (R-I) shown in Fig. 3, illustrate the presence of resonance stabilization. In the transition state of the reference reaction (R-II), the spin is mainly located on the two carbon atoms that exchange the hydrogen atom. For the transition state of (R-III) and (R-IV) it is observed that the Mulliken atomic spin density on the sulfur atom amounts to 0.08 . Since the spin delocalization is limited to the neighboring $\mathrm{S}$-atom, this resonance effect on the Arrhenius parameters is captured within the $\Delta G A V^{\circ}$ s. In the transition state of $(\mathrm{R}-\mathrm{I})$, spin delocalization indicates that both sulfur atoms are involved in delocalization of the unpaired electron in the transition state. Clearly, the spin density is distributed over the two carbon atoms exchanging the hydrogen atom and their neighboring $\mathrm{S}$ atoms. The electron delocalization in the transition state can be represented by the following resonance structures:

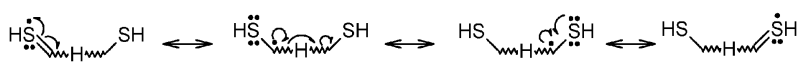

This electron delocalization effect cannot be captured within the $\Delta \mathrm{GAV}^{\mathrm{o}} \mathrm{s}$, as it originates from cross-interactions caused by the simultaneous presence of a sulfur ligand on the $\mathrm{C}_{1}$ and $\mathrm{C}_{2}$ groups.
(B)

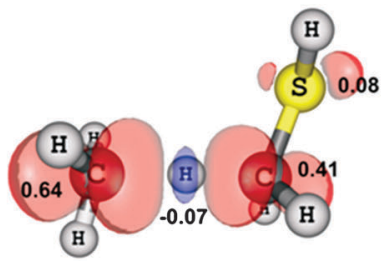

(C)

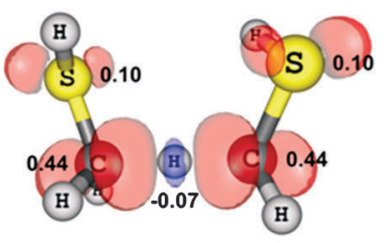

Fig. 3 Spin density plots and Mulliken atomic spin densities for the transition state of (A) hydrogen abstraction by methyl from methane (R-II), (B) hydrogen abstraction by methyl from methanethiol (R-III) and (R-IV), and (C) hydrogen abstraction by the methylenethiol radical from methanethiol $(\mathrm{R}-\mathrm{I})(\mathrm{B} 3 \mathrm{LYP} / 6-311 \mathrm{G}(2 \mathrm{~d}, \mathrm{~d}, \mathrm{p})$, contour value $=0.005)$. 
Therefore, a correction factor $\Delta E_{\mathrm{a} \text {,res }}^{\mathrm{o}}$ needs to be added to eqn (4) in order to account for the additional stabilization due to the simultaneous presence of resonance in the abstracting and the formed radical.

As shown by Sabbe et al., ${ }^{26}$ a relationship similar to eqn (4) can be used to model the single-event pre-exponential factor $\log \tilde{A}$ of a target reaction:

$$
\begin{aligned}
\log \tilde{A}(T)= & \log \tilde{A}_{\text {ref }}(T) \\
& +\sum_{i=1}^{2} \Delta \mathrm{GAV}_{\log \tilde{A}}^{\mathrm{o}}\left(C_{i}\right)+\Delta \log \tilde{A}_{\text {res }}^{\mathrm{o}}
\end{aligned}
$$

$\Delta \log \tilde{A}_{\text {res }}^{\text {o }}$ in eqn (5) accounts for the influence of crossinteractions between resonance structures on $\mathrm{C}_{1}$ and $\mathrm{C}_{2}$. The pre-exponential factor $A$ is then obtained by adding the number of single events, $n_{\mathrm{e}}$, to the single-event pre-exponential factor $\tilde{A}$ obtained from the GA method:

$$
\log A=\log \tilde{A}+\log n_{\mathrm{e}}
$$

$n_{\mathrm{e}}$ is analogous to the reaction path degeneracy and is given by the formula: ${ }^{50}$

$$
n_{\mathrm{e}}=\frac{n_{\mathrm{opt}, \ddagger}}{n_{\mathrm{opt}, \mathrm{A}} n_{\mathrm{opt}, \mathrm{B}}} \frac{\sigma_{\mathrm{A}} \sigma_{\mathrm{B}}}{\sigma_{\ddagger}}
$$

In eqn (7) $\sigma$ represents the total symmetry number of the molecule and $n_{\text {opt }}$ a correction factor accounting for the mixing of optically active species. In analogy with the single-event preexponential factor $\tilde{A}$, single-event standard reaction entropies $\Delta_{\mathrm{r}} \tilde{S}^{\mathrm{o}}$ and single-event rate coefficients $\tilde{k}$ are also used in this work.

\subsection{Symmetry numbers}

The total symmetry number of a molecule is equal to:

$$
\sigma=\sigma_{\mathrm{ext}} \prod_{i} \sigma_{\mathrm{int}, i}
$$

with $\sigma_{\text {ext }}$ and $\sigma_{\text {int }, i}$ the external and internal symmetry numbers. External symmetry numbers were obtained from the Gaussian 03 program. In case the reported experimental external symmetry number ${ }^{51}$ deviates from the one calculated by Gaussian 03 (see Table S8 in ESI $\dagger$ ), the experimental symmetry number was used to calculate the partition function. The internal symmetry number accounts for the symmetry of internal rotations. Methylene $\left(-\mathrm{C}^{\bullet} \mathrm{H}_{2}\right)$ and $i$-propylene $\left(-\mathrm{C}^{\bullet}\left(\mathrm{CH}_{3}\right)_{2}\right)$ rotating tops were assigned a symmetry number of 2 , in line with previous work on hydrocarbons. ${ }^{26}$

To account for nonsymmetrical torsion profiles, the various distinguishable structures can be calculated and their Boltzmann averaged contributions summed in order to obtain the total partition function. ${ }^{51}$ To avoid calculations for the various structures, the following approach was used: the higher energy conformers are neglected while for the energetically equivalent rotational minima the harmonic oscillator partition function of one of them is multiplied with a correction factor $n_{\text {conf }}$, which accounts for the mixing of the equivalent structures. ${ }^{50}$ This is equivalent to dividing the total symmetry number in eqn (8) by a factor $n_{\text {conf }}{ }^{52}$ For example, dihydrogen disulfide $\mathrm{H}_{2} \mathrm{~S}_{2}$ has an external twofold axis while internal rotation around the $\mathrm{S}-\mathrm{S}$ bond presents two distinct minima which are each other's mirror image, having the $\mathrm{S}-\mathrm{H}$ bonds nearly at right angles. To account for the two equivalent minima in $\mathrm{H}_{2} \mathrm{~S}_{2}$, Ercolani et al. ${ }^{52}$ proposed use of an apparent symmetry number of 1 , instead of 2 .

In analogy with previous work on hydrocarbons, $n_{\text {conf }}$ is not included in the $\Delta \mathrm{GAV}^{\mathrm{o}} \mathrm{s} .{ }^{26}$ Users of the GA method can opt to include these effects in the calculation of the pre-exponential factor by using an apparent symmetry number $\left(\sigma_{\text {app }}=\sigma / n_{\text {conf }}\right)$ in eqn (7), rather than the symmetry number defined by eqn (8).

\subsection{Tunneling}

It has been shown for hydrogen abstractions that, especially at lower temperatures, tunneling corrections have a profound effect on the calculated rate coefficients and thereby influence the Arrhenius parameters. ${ }^{29}$ Tunneling corrections are mainly temperature dependent and can differ significantly for the different reactions within a reaction family. Therefore, inclusion of the tunneling corrections in the $\Delta \mathrm{GAV}^{\mathrm{o}} \mathrm{s}$ would lead to temperature dependent $\Delta \mathrm{GAV}^{\mathrm{o}} \mathrm{s}$. A group additivity model hence benefits from separating tunneling contributions from the calculated Arrhenius parameters. Alternatively, tunneling can be modeled explicitly using correlations with other known properties of the reaction as exemplified in the reaction class transition state theory of Truong et $a l^{30,32,33}$ In the reaction class transition state theory, tunneling corrections for hydrogen abstractions are modeled by inclusion of a temperature dependent tunneling factor, which is taken as the ratio of the tunneling coefficients for a target reaction and the reference reaction. ${ }^{30}$

In this work, the Eckart method is used to determine the tunneling contributions. This method requires information concerning the imaginary frequency and both the forward and reverse barrier heights. However, those values are not accessible using the group additivity method presented in this work. Since tunneling can only occur through the net electronic barrier and as within the same reaction family imaginary frequencies and barrier heights are strongly related, the activation energy of the exothermic reaction can be considered as one of the main factors determining the tunneling contribution. For hydrogen abstraction reactions of the $\mathrm{C}-\mathrm{H}-\mathrm{C}$ type, Sabbe et al. ${ }^{26}$ have shown that tunneling contributions can be reproduced within a mean factor of deviation of 1.15 using a fourth order polynomial with temperature dependent coefficients:

$$
\kappa(T)=1+\left(\frac{162}{T}\right)^{3} E_{\mathrm{a}, \mathrm{exo}}+2.71 \times 10^{-6} \exp \left(-\frac{T-300}{26}\right) E_{\mathrm{a}, \mathrm{exo}}^{4}
$$

with $E_{\text {a,exo }}$ the activation energy for the exothermic reaction in $\mathrm{kJ} \mathrm{mol}^{-1}$. The parameters in eqn (9) were obtained by fitting to tunneling coefficients for 55 reactions. ${ }^{26}$ In Section 3.3.4 of this work the applicability of eqn (9) for the reactions studied in this work will be illustrated. Eckart tunneling coefficients for all reactions considered in this work at temperatures ranging from $300-1500 \mathrm{~K}$ are given in Table S7 of the ESI. $\dagger$ 


\section{Results and discussion}

\subsection{Rate coefficients and Arrhenius parameters}

Tunneling coefficients, Arrhenius parameters and rate coefficients at $300 \mathrm{~K}$ for 24 hydrogen abstraction reactions by methyl are shown in Table 1 . From the 24 reactions presented in Table 1 two sets of $23 \Delta \mathrm{GAV}^{\circ}$ s (both for the forward and reverse reaction directions) will be obtained. In Table 2 kinetic parameters at $300 \mathrm{~K}$ for six sets of reactions are presented to study the effect of secondary contributions and non-nearest-neighbor interactions (NNIs) on the Arrhenius parameters. In Table 3, tunneling coefficients, Arrhenius parameters and rate coefficients at $300 \mathrm{~K}$ are presented for an additional set of 32 reactions from which the influence of resonance in the transition state on the Arrhenius parameters can be studied. These 32 reactions involve hydrogen abstractions between allylic, propargylic, thiocarbonylic radicals, their methyl substituted analogues, alkyl radicals and carbon-centered radicals having a sulfur-atom in the $\alpha$-position of the radical site. Rate coefficients in the temperature range 300-1500 $\mathrm{K}$ and transition state geometries for all studied reactions can be found in the ESI. $\dagger$

Validating calculated data with experiment is of primary importance. However, in particular for sulfur chemistry, experimental data are scarce and for the few experiments available, rate coefficients are often obtained by fitting to simplified reaction mechanisms or were measured at such low pressures that pressure dependence can no longer be ignored. However, the few data that could be retrieved agree well with the rate coefficients reported in this work. Arthur and Lee ${ }^{53}$ report a rate coefficient at $500 \mathrm{~K}$ for the hydrogen abstraction from dimethyl sulfide by methyl of $4.1 \times 10 \mathrm{~m}^{3} \mathrm{~mol}^{-1} \mathrm{~s}^{-1}$. This agrees within a factor of 2 with the rate coefficient calculated in this work, i.e. $5.1 \times 10 \mathrm{~m}^{3} \mathrm{~mol}^{-1} \mathrm{~s}^{-1}$ (see ESI $\dagger$ ). Ekwenchi et al. ${ }^{54}$ studied hydrogen abstraction from an $\alpha$-carbon atom in diethyl sulfide by ethyl and obtained a rate coefficient $k=7.4 \times$ $10^{6} \exp (-3452 / T) \mathrm{m}^{3} \mathrm{~mol}^{-1} \mathrm{~s}^{-1}$ or $1.310^{4} \mathrm{~m}^{3} \mathrm{~mol}^{-1} \mathrm{~s}^{-1}$ at $400 \mathrm{~K}$. This rate coefficient is almost 3 orders of magnitude higher than for any reaction studied in this work. As the authors carefully reported their measurements, ${ }^{54}$ we were able to reassess the reported rate coefficient and obtain $k=6.2 \times$ $10^{4} \exp (-3765 / T) \mathrm{m}^{3} \mathrm{~mol}^{-1} \mathrm{~s}^{-1}$ in the temperature range 383-443 K. Details of this reassessment can be found in the ESI. $\dagger$ This rate coefficient agrees within a factor of 5 with the calculated rate coefficients obtained for similar reactions, such as hydrogen abstraction by ethyl from a secondary $\alpha$-C atom in ethanethiol or ethyl vinyl sulfide (reactions (40) and (41)). Estimated rate coefficients for hydrogen abstraction reactions by methyl from diethyl sulfide are reported by Zheng et al. ${ }^{9}$ At $1000 \mathrm{~K}$ our rate coefficients agree within one order of magnitude with their data.

The reactions studied in Tables 1 and 2 are hydrogen abstraction reactions by the methyl and ethyl radical from a carbon atom adjacent to a sulfur atom or a thiocarbonyl group. All reactions in Tables 1 and 2 are exothermic with the exception of the two abstraction reactions from thiophene (reactions (23) and (24)). The entropy change during reaction fluctuates around $0 \mathrm{~J} \mathrm{~mol}^{-1} \mathrm{~K}^{-1}$, as both the breaking and forming bonds during reaction are the same, i.e. a $\mathrm{C}-\mathrm{H}$ bond.
At $300 \mathrm{~K}$, the rate coefficients range between $3.7 \times 10^{-24}$ up to $9.0 \times 10^{2} \mathrm{~m}^{3} \mathrm{~mol}^{-1} \mathrm{~s}^{-1}$. The lowest rate coefficient is obtained for hydrogen abstraction from methane by the $\mathrm{CH}_{3} \mathrm{C}^{\bullet}(\mathrm{SH}) \mathrm{C}(=\mathrm{S}) \mathrm{H}$ radical (reaction (13)). The activation energy for this reaction amounts to $172 \mathrm{~kJ} \mathrm{~mol}^{-1}$, which is the highest value obtained among all reactions studied in this work. The high barrier is caused by the stability of the $\mathrm{CH}_{3} \mathrm{C}^{\bullet}(\mathrm{SH}) \mathrm{C}(=\mathrm{S}) \mathrm{H}$ radical, resulting from (a) hyperconjugation, (b) $\pi$-conjugation with the adjacent thiocarbonyl group and (c) the $\alpha$-effect due to the presence of a neighboring $\mathrm{S}$ atom. The lowest barriers are obtained for abstraction of hydrogen in the $\alpha$ position of a $\mathrm{C}=\mathrm{S}$ group by methyl (reactions (5)-(7)) and for hydrogen abstraction from methane by the thiofen-2-yl radical (reaction (23)). Adjacent $\mathrm{C}=\mathrm{S}$ groups significantly ease hydrogen abstraction, as in the resulting radical most spin will be evacuated to the sulfur atom.

At $300 \mathrm{~K}$ tunneling coefficients (Tables 1-3) are significant and range between 2 and 52. For hydrogen abstraction reactions by the methyl radical (Table 1), pre-exponential factors fluctuate between $10^{5}$ and $10^{7} \mathrm{~m}^{3} \mathrm{~mol}^{-1} \mathrm{~s}^{-1}$. This is somewhat higher than the values obtained for the reactions presented in Table 3 having a resonance stabilized transition state and for which the pre-exponential factor ranges around $10^{4.8}$. The higher pre-exponential factors obtained for hydrogen abstraction reactions involving methyl are due to the higher reaction path degeneracy.

The presented data show that the reaction enthalpy and the activation energy are strongly correlated. This can also be seen from Fig. 4, in which the activation energies for the reactions presented in Table 1 are shown as a function of the reaction enthalpy. A Blowers and Masel curve (eqn (10)) is fitted to the data: ${ }^{17}$

$$
E_{\mathrm{a}}=\left(\frac{w_{\mathrm{b}}+w_{\mathrm{f}}+\Delta_{\mathrm{r}} H}{2}\right) \frac{\left(V_{\mathrm{p}}-\left(w_{\mathrm{b}}+w_{\mathrm{f}}\right)+\Delta_{\mathrm{r}} H\right)^{2}}{V_{\mathrm{p}}{ }^{2}-\left(w_{\mathrm{b}}+w_{\mathrm{f}}\right)^{2}+\Delta_{\mathrm{r}} H^{2}}
$$

Since typical $\mathrm{C}-\mathrm{H}$ bond energies range around $400 \mathrm{~kJ} \mathrm{~mol}^{-1}$, the parameter $w_{\mathrm{b}}+w_{\mathrm{f}}$ was set to $800 \mathrm{~kJ} \mathrm{~mol}^{-1}$. A leastsquares fit resulted in a $V_{\mathrm{p}}$ of $1114 \mathrm{~kJ} \mathrm{~mol}^{-1}$, corresponding to an intrinsic barrier $E_{\mathrm{a}}^{\mathrm{o}}$ of $65.7 \mathrm{~kJ} \mathrm{~mol}^{-1}$. The Blowers and Masel model succeeds in reproducing the calculated activation energies on average within $6 \mathrm{~kJ} \mathrm{~mol}^{-1}$. However, maximum deviations can amount up to $21 \mathrm{~kJ} \mathrm{~mol}^{-1}$.

For hydrogen abstractions by the methyl radical, barriers for rotation about the transition state bond are limited to $1 \mathrm{~kJ} \mathrm{~mol}^{-1}$. Treating these rotations as free rotors significantly decreases the rate coefficients with at most a factor of 3 at $300 \mathrm{~K}$ up to a factor of 7 at $1500 \mathrm{~K}$. For the reactions presented in Table 3 rotational barriers vary between 1 up to $13 \mathrm{~kJ} \mathrm{~mol}^{-1}$. The higher barriers for rotation are due to steric effects and are in particular observed for reactions involving thiocarbonyl compounds.

\subsection{Resonance interactions}

The group additivity model for Arrhenius parameters of hydrogen abstraction reactions can be significantly improved by introducing correction factors that account for crossresonance and/or hyperconjugative effects in the transition state. $^{26}$ To model resonance effects in the transition states of 
Table 1 Tunneling coefficients $\kappa(-)$, standard reaction enthalpies $\Delta_{\mathrm{r}} H^{\circ}\left(\mathrm{kJ} \mathrm{mol}^{-1}\right)$, standard reaction entropies $\Delta_{\mathrm{r}} S^{\mathrm{o}}\left(\mathrm{J}\right.$ mol $\left.{ }^{-1} \mathrm{~K}^{-1}\right)$, preexponential factors $\log A\left(\log \left(\mathrm{m}^{3} \mathrm{~mol}^{-1} \mathrm{~s}^{-1}\right)\right)$, activation energies $E_{\mathrm{a}}\left(\mathrm{kJ} \mathrm{mol}^{-1}\right)$ and rate coefficients $k\left(\mathrm{~m}^{3} \mathrm{~mol}^{-1} \mathrm{~s}^{-1}\right)$ at $300 \mathrm{~K}$ for the training set

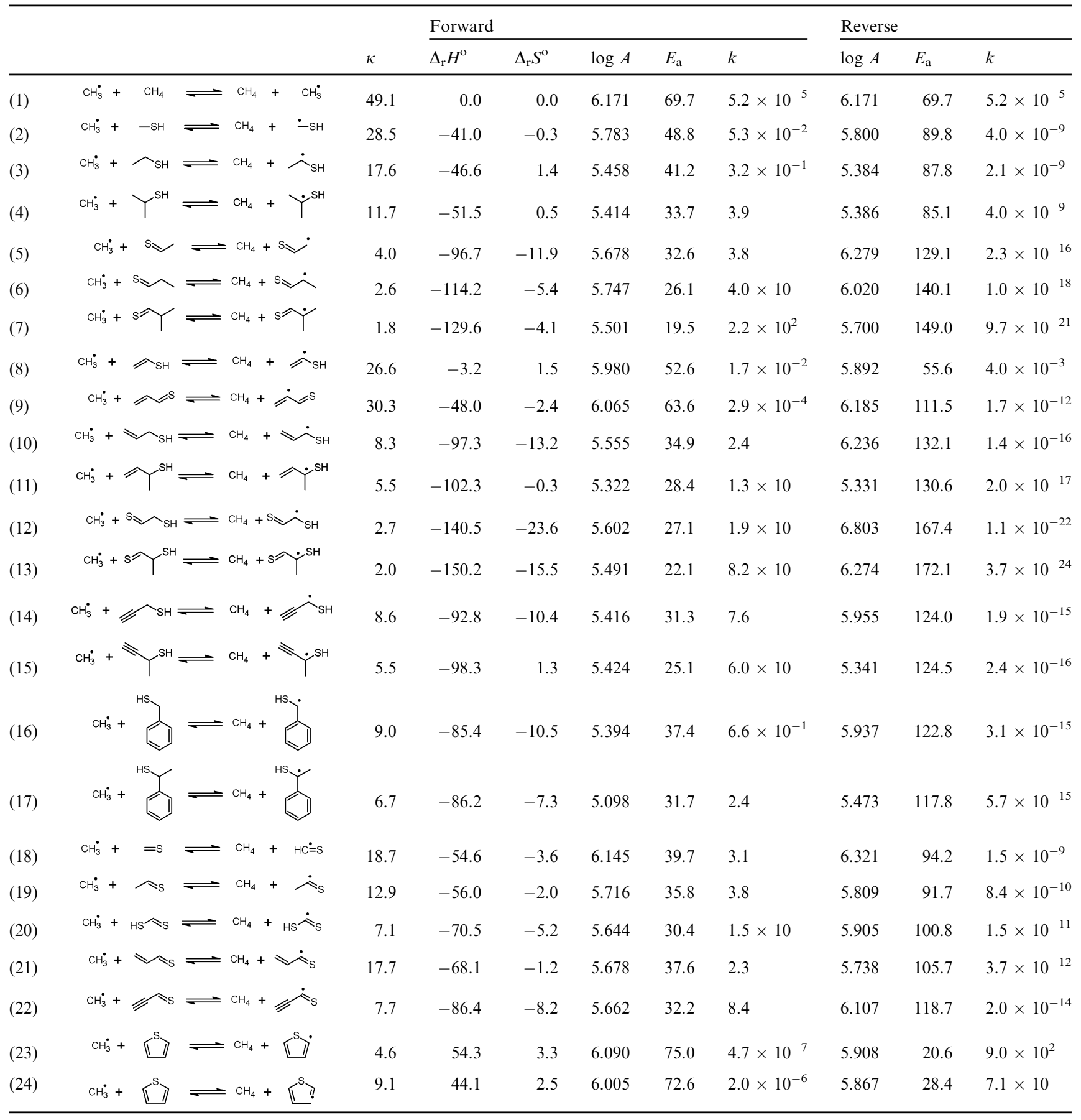

hydrogen abstraction reactions involving hydrocarbons, four resonance corrections were introduced. ${ }^{26}$ These four corrections account for the stabilization in the transition state due to the simultaneous presence of hyperconjugating and $\pi$-conjugating groups on the $\mathrm{C}_{1}$ and $\mathrm{C}_{2}$ atoms. To describe hydrogen abstractions from thiols, sulfides and thiocarbonyl compounds, additional corrections need to be introduced accounting for cross-interactions involving S- and CS-ligands.

To determine the resonance corrections needed to model hydrogen abstraction reactions from organosulfur compounds,
Arrhenius parameters and rate coefficients were gathered for the 32 reactions presented in Table 3 . These reactions allow us to study the resonance stabilization caused by (a) cross-interactions of a sulfur ligand on the $\mathrm{C}_{1}$ atom with hyperconjugating $\mathrm{C}-\mathrm{H}$ bonds, $\pi$-sulfur atoms or $\pi$-conjugating systems on the $\mathrm{C}_{2}$ atom (reactions (42)-(59)) and (b) cross-interactions of a thiocarbonyl group on the $\mathrm{C}_{1}$ atom with hyperconjugating $\mathrm{C}-\mathrm{H}$ bonds, $\alpha$-sulfur atoms or $\pi$-conjugating systems on the $C_{2}$ atom (reactions (60)-(73)). Besides the 4 corrections previously introduced for hydrogen abstractions between hydrocarbons, 
Table 2 Tunneling coefficients $\kappa(-)$, standard reaction enthalpies $\Delta_{\mathrm{r}} H^{\circ}\left(\mathrm{kJ} \mathrm{mol}^{-1}\right)$, single-event standard reaction entropies $\Delta_{\mathrm{r}} S^{\mathrm{o}}\left(\mathrm{J}\right.$ mol $\left.{ }^{-1} \mathrm{~K}^{-1}\right)$, single-event pre-exponential factors $\log \tilde{A}\left(\log \left(\mathrm{m}^{3} \mathrm{~mol}^{-1} \mathrm{~s}^{-1}\right)\right)$, activation energies $E_{\mathrm{a}}\left(\mathrm{kJ} \mathrm{mol}^{-1}\right)$ and single-event rate coefficients $\tilde{k}\left(\mathrm{~m}^{3} \mathrm{~mol}{ }^{-1} \mathrm{~s}^{-1}\right)$ at $300 \mathrm{~K}$ for the 21 hydrogen abstraction reactions from which the influence of secondary contributions and non-nearest-neighbor interactions is studied

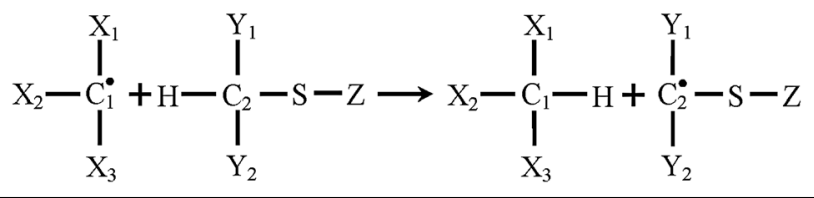

\begin{tabular}{|c|c|c|c|c|c|c|c|c|c|c|}
\hline & & \multirow[b]{2}{*}{$\kappa$} & \multicolumn{5}{|c|}{ Forward } & \multicolumn{3}{|c|}{$\underline{\text { Reverse }}$} \\
\hline & & & $\Delta_{\mathrm{r}} H^{\mathrm{o}}$ & $\Delta_{\mathrm{r}} \tilde{S}^{\mathrm{o}}$ & $\log \tilde{A}$ & $E_{\mathrm{a}}$ & $\tilde{k}$ & $\log \tilde{A}$ & $E_{\mathrm{a}}$ & $\tilde{k}$ \\
\hline & \multicolumn{10}{|l|}{ Y-group } \\
\hline (3) & 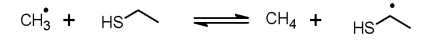 & 17.6 & -46.6 & 7.2 & 5.157 & 41.2 & $1.6 \times 10^{-1}$ & 4.782 & 87.8 & $5.2 \times 10^{-10}$ \\
\hline (25) & $\mathrm{CH}_{3}^{\dot{3}}+\mathrm{HS}^{\sim} \rightleftharpoons \mathrm{CH}_{4}+\mathrm{HS}$ & 19.2 & -45.6 & 5.9 & 4.984 & 40.5 & $1.6 \times 10^{-1}$ & 4.671 & 86.1 & $8.7 \times 10^{-10}$ \\
\hline (26) & $=\mathrm{CH}_{4}+\mathrm{HS}^{-}$ & 18.4 & -46.8 & 6.3 & 5.090 & 39.9 & $2.5 \times 10^{-1}$ & 4.758 & 86.6 & $8.4 \times 10^{-10}$ \\
\hline (27) & $\mathrm{CH}_{3}^{\cdot}+\mathrm{HS}^{\Upsilon}$ & 20.0 & -45.2 & 5.5 & 4.914 & 40.8 & $1.2 \times 10^{-1}$ & 4.624 & 86.0 & $8.6 \times 10^{-10}$ \\
\hline (28) & $\mathrm{CH}_{3}^{\circ}+\mathrm{HS}^{\mathrm{K}}=$ & 22.0 & -41.9 & 9.0 & 4.893 & 40.6 & $1.4 \times 10^{-1}$ & 4.418 & 82.5 & $2.4 \times 10^{-9}$ \\
\hline (8) & $\mathrm{CH}_{3}^{\cdot}+\mathrm{HS} \curvearrowright \rightleftharpoons \mathrm{CH}_{4}+\mathrm{HS}$ & 26.6 & -3.2 & 1.5 & 5.378 & 52.6 & $4.3 \times 10^{-3}$ & 5.290 & 55.6 & $1.0 \times 10^{-3}$ \\
\hline (29) & $\mathrm{CH}_{3}^{\dot{2}}+\mathrm{HS}^{\curvearrowright} \rightleftharpoons \mathrm{CH}_{4}+\mathrm{HS}^{-}$ & 25.4 & -3.0 & -3.4 & 5.058 & 52.0 & $2.5 \times 10^{-3}$ & 5.228 & 54.9 & $1.1 \times 10^{-3}$ \\
\hline \multirow[t]{2}{*}{ (30) } & $\mathrm{CH}_{3}^{-}+\mathrm{HS}^{\Uparrow} \rightleftharpoons \mathrm{CH}_{4}+\mathrm{HS}^{-}$ & 27.9 & -7.2 & -6.5 & 4.706 & 48.2 & $5.5 \times 10^{-3}$ & 5.030 & 55.3 & $6.6 \times 10^{-4}$ \\
\hline & \multicolumn{10}{|l|}{ Z-group } \\
\hline (2) & $\mathrm{CH}_{3}^{\cdot}+\mathrm{HS}-=\mathrm{CH}_{4}+\mathrm{HS}$ & 28.5 & -41.0 & 2.1 & 4.704 & 48.8 & $4.5 \times 10^{-3}$ & 4.595 & 89.8 & $2.5 \times 10^{-10}$ \\
\hline (31) & $\mathrm{CH}_{3}^{\dot{3}}+-\mathrm{S}=\Longrightarrow \mathrm{CH}_{4}+$ & 23.3 & -46.2 & -0.3 & 4.653 & 46.1 & $9.4 \times 10^{-3}$ & 4.666 & 92.3 & $8.7 \times 10^{-11}$ \\
\hline (32) & $\mathrm{CH}_{3}^{\prime}+\widehat{八}^{\prime} \rightleftharpoons \mathrm{CH}_{4}+\widehat{八}^{\prime}$ & 28.5 & -42.0 & -1.3 & 5.151 & 52.0 & $3.4 \times 10^{-3}$ & 5.212 & 93.9 & $1.9 \times 10^{-10}$ \\
\hline (33) & $\mathrm{CH}_{3}^{-}+\mathrm{HS}^{\mathrm{S}} \mathrm{C}_{-} \rightleftharpoons \mathrm{CH}_{4}+\mathrm{HS}^{S} \mathrm{~S}_{-}$. & 29.1 & -36.6 & -1.8 & 4.677 & 47.6 & $6.8 \times 10^{-3}$ & 4.768 & 84.2 & $3.6 \times 10^{-9}$ \\
\hline (3) & $\mathrm{CH}_{3}^{\circ}+\mathrm{HS} \frown=\mathrm{CH}_{4}+\mathrm{HS}$ & 17.6 & -46.6 & 7.2 & 5.157 & 41.2 & $1.6 \times 10^{-1}$ & 4.782 & 87.8 & $5.2 \times 10^{-10}$ \\
\hline (34) & $\Longrightarrow \mathrm{CH}_{4}+\gamma_{\mathrm{S}}$ & 14.9 & -51.9 & 8.2 & 5.108 & 38.5 & $3.7 \times 10^{-1}$ & 4.677 & 90.4 & $1.3 \times 10^{-10}$ \\
\hline (35) & $\rightleftharpoons \mathrm{CH}_{4}+\mathrm{HS}$ & 19.4 & -44.0 & 13.0 & 5.145 & 40.4 & $2.4 \times 10^{-1}$ & 4.468 & 84.4 & $1.1 \times 10^{-9}$ \\
\hline (36) & $=\mathrm{CH}_{4}+-\mathrm{S}$ & 19.1 & -45.7 & -4.5 & 5.028 & 41.0 & $1.4 \times 10^{-1}$ & 5.239 & 86.5 & $2.7 \times 10^{-9}$ \\
\hline (37) & $\mathrm{CH}_{3}^{\cdot}+\mathrm{S}_{\mathrm{S}} \widehat{ } \rightleftharpoons \mathrm{CH}_{4}+{ } \mathrm{S}$. & 19.4 & -44.6 & 11.5 & 4.985 & 41.0 & $1.3 \times 10^{-1}$ & 4.387 & 85.6 & $5.6 \times 10^{-10}$ \\
\hline (38) & $\mathrm{CH}_{3}^{\circ}+\widehat{ح S}_{\mathrm{S}} \rightleftharpoons \mathrm{CH}_{4}+\widehat{ح S}_{\mathrm{S}}$ & 18.4 & -47.8 & 8.7 & 5.513 & 44.0 & $1.3 \times 10^{-1}$ & 5.054 & 91.8 & $2.1 \times 10^{-10}$ \\
\hline (10) & $\mathrm{CH}_{3}+\mathrm{HS} \rightleftharpoons \mathrm{CH}_{4}+{ }_{\mathrm{HS}} \dot{\Upsilon}$ & 8.3 & -97.3 & -1.7 & 5.254 & 34.9 & 1.2 & 5.333 & 132.1 & $1.7 \times 10-{ }^{17}$ \\
\hline (39) & 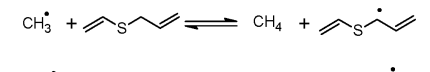 & 7.8 & -99.7 & -6.1 & 5.292 & 34.5 & 1.4 & 5.600 & 134.1 & $1.3 \times 10^{-17}$ \\
\hline (40) & $\dot{-}+\mathrm{HS} \rightleftharpoons-+{ }_{\mathrm{HS}} \dot{\Upsilon}$ & 29.4 & -31.1 & -9.8 & 4.256 & 43.5 & $1.3 \times 10^{-2}$ & 4.764 & 74.6 & $1.7 \times 10^{-7}$ \\
\hline (41) & $\dot{-}+\widehat{八}_{\mathrm{s}} \rightleftharpoons-+\widehat{八}_{\mathrm{s}} \dot{\boldsymbol{\gamma}}$ & 25.1 & -36.4 & -8.8 & 4.141 & 40.5 & $2.9 \times 10^{-2}$ & 4.593 & 76.9 & $3.8 \times 10^{-8}$ \\
\hline
\end{tabular}

8 additional corrections are required to capture all possible cross-interactions with S- and CS-ligands. The 8 new corrections account for the cross-interaction of (a) an $\alpha$-sulfur atom with a $\beta \mathrm{C}-\mathrm{H}$ bond $\left(\mathrm{p}_{\alpha \mathrm{S}}-\sigma_{\beta \mathrm{C}-\mathrm{H}}\right)$, (b) an $\alpha$-sulfur atom with a $\pi$-conjugating system (both allylic, propargylic or phenylic)

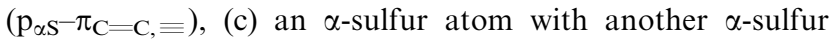
atom $\left(\mathrm{p}_{\alpha \mathrm{S}}-\mathrm{p}_{\alpha \mathrm{S}}\right),(\mathrm{d})$ a thiocarbonyl group with a $\beta \mathrm{C}-\mathrm{H}$ bond $\left(\pi_{\mathrm{C}=\mathrm{S}}-\sigma_{\beta \mathrm{C}-\mathrm{H}}\right)$, (e) a thiocarbonyl group with a $\mathrm{C}=\mathrm{C}$ group
$\left(\pi_{\mathrm{C}=\mathrm{S}}-\pi_{\mathrm{C}=\mathrm{C}}\right.$ ), (f) a thiocarbonyl group with a $\mathrm{C} \equiv \mathrm{C}$ group $\left(\pi_{\mathrm{C}=\mathrm{S}}-\pi_{\equiv}\right)$, (g) a thiocarbonyl group with another thiocarbonyl group ( $\pi_{\mathrm{C}=\mathrm{S}}-\pi_{\mathrm{C}=\mathrm{S}}$ ) and (h) a thiocarbonyl group with an $\alpha$-sulfur atom $\left(\pi_{\mathrm{C}=\mathrm{S}}-\mathrm{p}_{\alpha \mathrm{S}}\right)$. Spin density plots illustrating the electron delocalization in the transition state for the newly introduced resonance corrections are presented in the ESI. $\dagger$

Each of the 8 introduced resonance corrections accounts for the simultaneous presence of one ligand on the $C_{1}$ atom with 
Table 3 Tunneling coefficients $\kappa(-)$, standard reaction enthalpies $\Delta_{\mathrm{r}} H^{\circ}\left(\mathrm{kJ} \mathrm{mol}^{-1}\right)$, standard reaction entropies $\Delta_{\mathrm{r}} S^{\circ}\left(\mathrm{J}\right.$ mol $\left.{ }^{-1} \mathrm{~K}{ }^{-1}\right)$, preexponential factors $\log A\left(\log \left(\mathrm{m}^{3} \mathrm{~mol}^{-1} \mathrm{~s}^{-1}\right)\right)$, activation energies $E_{\mathrm{a}}\left(\mathrm{kJ} \mathrm{mol}^{-1}\right)$ and rate coefficients $k\left(\mathrm{~m}^{3} \mathrm{~mol}^{-1} \mathrm{~s}^{-1}\right)$ at $300 \mathrm{~K}_{\text {for the }} 32 \mathrm{hydrogen}$ abstraction reactions from which the effect of resonance in the transition state on the Arrhenius parameters is studied

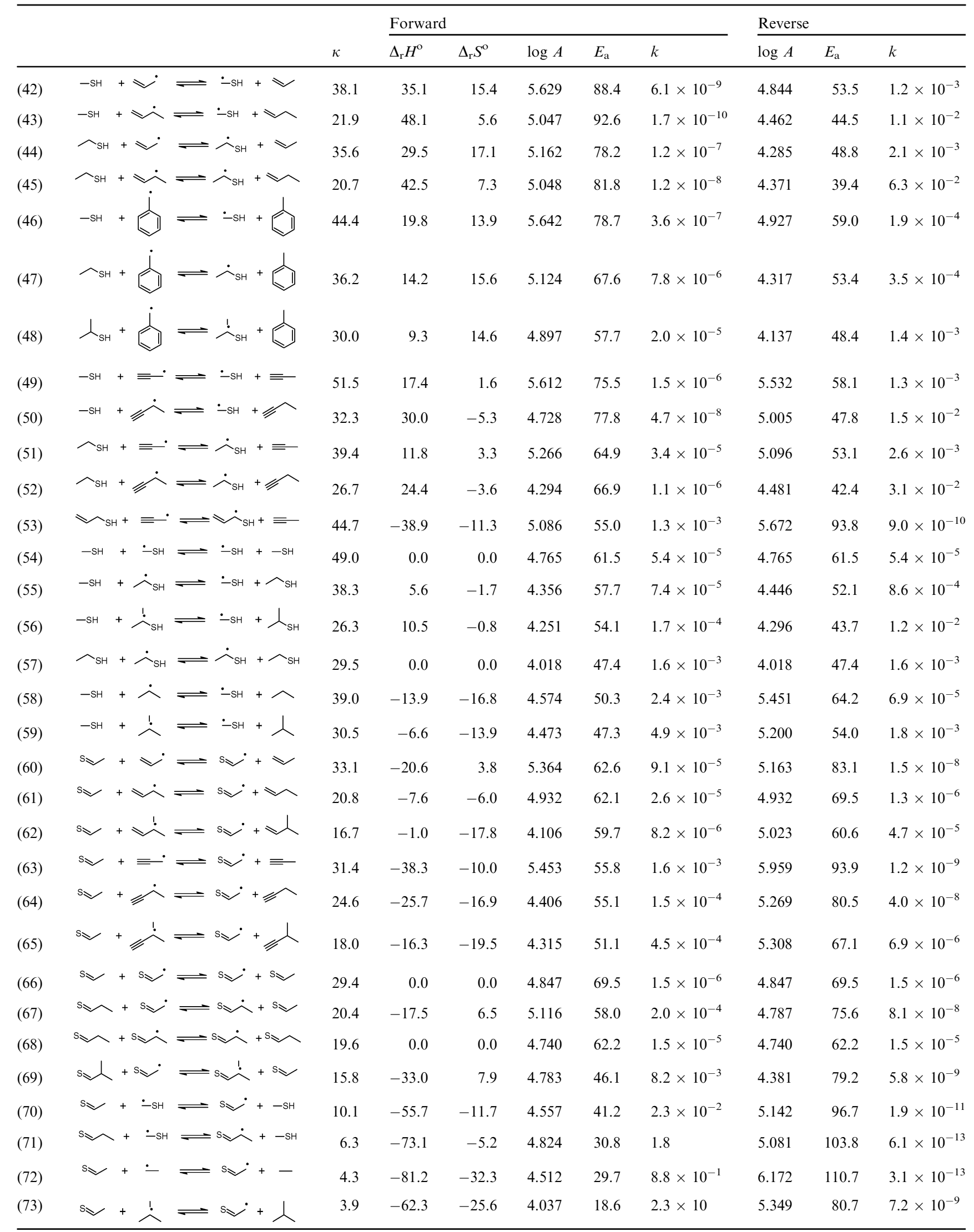




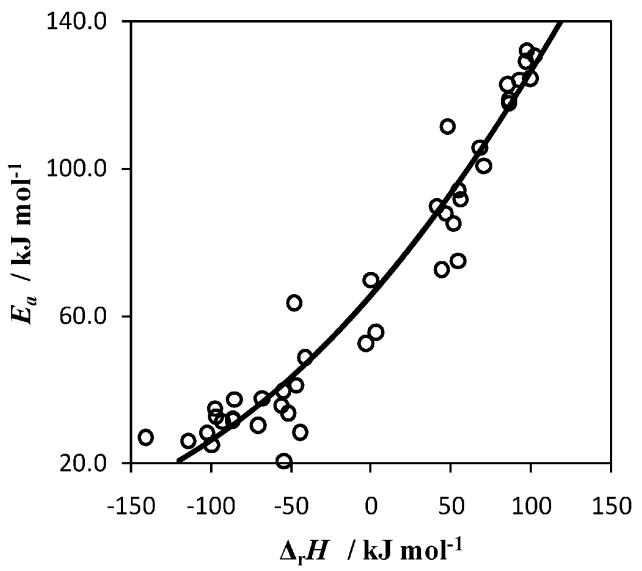

Fig. 4 Bell-Evans-Polanyi plot for the hydrogen abstraction reactions presented in Table 2. The full line corresponds to the Blowers and Masel model using $w_{\mathrm{b}}+w_{\mathrm{f}}=800 \mathrm{~kJ} \mathrm{~mol}^{-1}$ and $V_{\mathrm{p}}=1114 \mathrm{~kJ} \mathrm{~mol}^{-1}$.

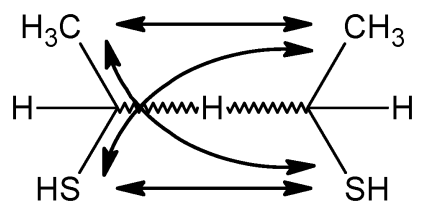

Fig. 5 Resonance interactions in the transition state of the symmetrical hydrogen abstraction reaction between ethylenethiol $\left(\mathrm{CH}_{3} \mathrm{C}^{\bullet} \mathrm{HSH}\right)$ and ethanethiol $\left(\mathrm{CH}_{3} \mathrm{CH}_{2} \mathrm{SH}\right)$.

one ligand on the $\mathrm{C}_{2}$ atom, or vice versa. For example, $\mathrm{p}_{\alpha \mathrm{S}}-\mathrm{p}_{\alpha \mathrm{S}}$ accounts for the interaction of one sulfur atom bonded to the $\mathrm{C}_{1}$ atom with one sulfur atom bonded to the $\mathrm{C}_{2}$ atom. The number of corrections needed to describe the additional stabilization in the transition state due to cross-effects is obtained by counting all the cross interactions between ligands of the $\mathrm{C}_{1}$ and $\mathrm{C}_{2}$ groups. For example, the transition state for the hydrogen abstraction from methanethiol by the $i$-propyl radical (reaction (58)) is stabilized by the interaction of two hyperconjugating $\mathrm{C}-\mathrm{H}$ bonds on the $\mathrm{C}_{1}$ group with one $\alpha$-sulfur atom on the $\mathrm{C}_{2}$ group (see Fig. S7 of the ESI $\dagger$ ). The additional transition state stabilization in reaction (58) is therefore equal to twice $\mathrm{p}_{\alpha \mathrm{S}}-\sigma_{\beta \mathrm{C}-\mathrm{H}}$. However, for more complex reactions resonance corrections can easily be overlooked and therefore as general aid eqn (11) and (12) can be applied:

$$
\begin{gathered}
n(\mathrm{X}-\mathrm{X})=n_{\mathrm{X}, \mathrm{C}_{1}} n_{\mathrm{X}, \mathrm{C}_{2}} \\
n(\mathrm{X}-\mathrm{Y})=n_{\mathrm{X}, \mathrm{C}_{1}} n_{\mathrm{Y}, \mathrm{C}_{2}}+n_{\mathrm{Y}, \mathrm{C}_{1}} n_{\mathrm{X}, \mathrm{C}_{2}}
\end{gathered}
$$

with $\mathrm{X}, \mathrm{Y}=\mathrm{p}_{\alpha \mathrm{S}}, \sigma_{\beta \mathrm{C}-\mathrm{H}}, \pi_{\mathrm{C}=\mathrm{C}}, \pi \equiv$ or $\pi_{\mathrm{C}=\mathrm{S}} \cdot n(\mathrm{X}-\mathrm{X})$ in eqn (11) is the number of resonance corrections needed to describe the cross-interactions caused by the simultaneous presence of the same $X$ ligand on both the $\mathrm{C}_{1}$ and $\mathrm{C}_{2}$ atoms. $n(\mathrm{X}-\mathrm{Y})$ in eqn (12) represents the number of cross-interactions between two different ligands, $\mathrm{X}$ and $\mathrm{Y}$, on the $\mathrm{C}_{1}$ and $\mathrm{C}_{2}$ atoms. $n_{\mathrm{X}, \mathrm{C}_{1}}$ and $n_{\mathrm{X}, \mathrm{C}_{2}}$ represent the number of $\mathrm{X}$ ligands on $\mathrm{C}_{1}$ and $\mathrm{C}_{2}$, respectively, while $n_{\mathrm{Y}, \mathrm{C}_{1}}$ and $n_{\mathrm{Y}, \mathrm{C}_{2}}$ are the number of $\mathrm{Y}$ ligands on $\mathrm{C}_{1}$ and $\mathrm{C}_{2}$, respectively. The use of eqn (11) and (12) is illustrated for the symmetrical hydrogen abstraction reaction by ethylenethiol $\left(\mathrm{CH}_{3} \mathrm{C}^{\bullet} \mathrm{HSH}\right)$ from ethanethiol $\left(\mathrm{CH}_{3} \mathrm{CH}_{2} \mathrm{SH}\right)$. Fig. 5 illustrates that the transition state of this reaction is stabilized by three types of cross-interactions: (a) between $\alpha-S$ atoms on both $C_{1}$ and $C_{2} \quad\left(p_{\alpha} S-p_{\alpha} S\right)$, (b) between $\alpha-\mathrm{S}$ atoms and a $\beta \mathrm{C}-\mathrm{H}$ bond $\left(\mathrm{p}_{\alpha} \mathrm{S}-\sigma_{\beta} \mathrm{C}-\mathrm{H}\right)$ and (c) between $\beta \mathrm{C}-\mathrm{H}$ bonds on both $\mathrm{C}_{1}$ and $\mathrm{C}_{2}\left(\sigma_{\beta} \mathrm{C}-\mathrm{H}-\sigma_{\beta} \mathrm{C}-\mathrm{H}\right)$. The number of $\mathrm{p}_{\alpha} \mathrm{S}-\mathrm{p}_{\alpha} \mathrm{S}$ and $\sigma_{\beta} \mathrm{C}-\mathrm{H}-\sigma_{\beta} \mathrm{C}-\mathrm{H}$ corrections can be obtained from eqn (11), while eqn (12) accounts for the number of $\mathrm{p}_{\alpha} \mathrm{S}-\sigma_{\beta} \mathrm{C}-\mathrm{H}$ corrections required. The number of hyperconjugating $\mathrm{C}-\mathrm{H}$ bonds on the $\mathrm{C}_{1}$ and $\mathrm{C}_{2}$ atoms amounts to $1\left(n_{\sigma} \beta \mathrm{C}-\mathrm{H}, \mathrm{C}_{1}=\right.$ $\left.n_{\sigma} \beta \mathrm{C}-\mathrm{H}, \mathrm{C}_{2}=1\right)$. Also the number of $\mathrm{S}$ ligands on both primary groups is equal to $1\left(n_{\mathrm{p \alpha}} \mathrm{S}, \mathrm{C}_{1}=n_{\mathrm{p \alpha}} \mathrm{S}, \mathrm{C}_{2}=1\right)$. Therefore the total amount of corrections needed to describe the resonance in this transition state amounts to $2 \mathrm{p}_{\alpha} \mathrm{S}-\sigma_{\beta} \mathrm{C}-\mathrm{H}$ corrections, $1 \mathrm{p}_{\alpha} \mathrm{S}-\mathrm{p}_{\alpha} \mathrm{S}$ correction and $1 \sigma_{\beta} \mathrm{C}-\mathrm{H}-\sigma_{\beta} \mathrm{C}-\mathrm{H}$ correction.

\subsection{Group additivity model}

3.3.1 Group additivity values. The data presented in Table 1 can be used to calculate $\Delta G A V^{o}$ s for hydrogen abstraction reactions by/from carbon atoms having a sulfur or a thiocarbonyl ligand. The hydrogen abstraction from methane by methyl was chosen as the reference reaction. This ensures that the $\Delta \mathrm{GAV}^{\mathrm{o}} \mathrm{s}$ presented in this work can be combined with the ones reported in previous work for hydrogen abstraction reactions between hydrocarbons. ${ }^{26}$ Arrhenius parameters at different temperatures for the reference reaction can be found in Table S1 of the ESI. $\dagger \Delta \mathrm{GAV}^{\circ} \mathrm{s}$ for both the pre-exponential factor and activation energy at 300 and $1000 \mathrm{~K}$ can be found in Table 4.

The derivation of the $\Delta \mathrm{GAV}^{\mathrm{o}} \mathrm{s}$ is straightforward. For example, $\Delta \mathrm{GAV}_{E_{\mathrm{a}}}^{\mathrm{o}}\left(\mathrm{CS}_{2}-(\mathrm{H})\right)$ at $300 \mathrm{~K}$ can be obtained by subtracting the $E_{\mathrm{a}}$ of the reference reaction from the value obtained for reaction (18), i.e. $39.7-69.7=-30.0 \mathrm{~kJ} \mathrm{~mol}^{-1}$. Similarly, $\Delta \mathrm{GAV}_{\log \tilde{A}}^{\mathrm{o}}\left(\mathrm{C}_{2}-(\mathrm{S})(\mathrm{H})_{2}\right)$ is obtained by subtracting the $\log \tilde{A}$ of the reference reaction from the $\log \tilde{A}$ obtained for reaction (18). The number of single events for the reference reaction equals 8 , resulting in $\log \tilde{A}_{\text {ref }}=6.171-\log (8)=$ 5.267, while $n_{\mathrm{e}}$ for reaction (18) is equal to 4, leading to $\log \tilde{A}=$ $6.145-\log (4)=5.543$. The $\Delta \mathrm{GAV}_{\log \tilde{A}}^{\mathrm{o}}\left(\mathrm{CS}_{2}-(\mathrm{H})\right)$ is the difference between both values and equals $5.543-5.267=$ +0.276 . The reaction path degeneracy of 4 for reaction (18) is obtained by multiplying the number of equivalent hydrogen atoms in thioformaldehyde $(=2)$ with a factor of two accounting for the two equivalent sites of the methyl radical which can abstract the hydrogen atom.

From Table 4 it can be seen that the $\Delta \mathrm{GAV}^{\mathrm{o}} \mathrm{s}$ are almost independent of temperature. The $\Delta \mathrm{GAV}_{E_{\mathrm{a}}}^{\mathrm{o}}\left(\mathrm{C}_{1}\right) \mathrm{s}$ increase on average by $3 \mathrm{~kJ} \mathrm{~mol}^{-1}$ in going from 300 to $1000 \mathrm{~K}$. The $\Delta \mathrm{GAV}_{E_{\mathrm{a}}}^{\mathrm{o}}\left(\mathrm{C}_{2}\right)$ s change at most by $1 \mathrm{~kJ} \mathrm{~mol}^{-1}$ and prove to be temperature independent. This can also be seen from Fig. 6 showing the temperature dependence of the $\mathrm{C}_{1}$ and $\mathrm{C}_{2}$ groups in the temperature range 300-1500 K. In general, the temperature dependence is small and restricted to $4 \mathrm{~kJ} \mathrm{~mol}^{-1}$ for $\Delta \mathrm{GAV}_{E_{\mathrm{a}}}^{\mathrm{o}}$ and

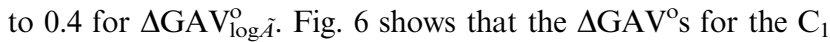
groups are slightly more dependent on the temperature than those obtained for the $\mathrm{C}_{2}$ groups. The changes in $E_{\mathrm{a}}$ and $\log \tilde{A}$ for the $\mathrm{C}_{2}$ contributions are limited to $1 \mathrm{~kJ} \mathrm{~mol}^{-1}$ and 0.1 , respectively. A more pronounced temperature dependence is observed for the $C_{1}-(S)\left(C_{t}\right)(C)$ group. This different behavior is caused by a free methyl rotor in the 3-sulfanylbut-1-yn-3-yl radical, 
Table $4 \Delta \mathrm{GAV}^{\mathrm{o}} \mathrm{s}$ at 300 and $1000 \mathrm{~K}$ for abstractions of a hydrogen atom bonded to a carbon-centered group by a carbon-centered radical $\left(\Delta \mathrm{GAV}_{\log \tilde{A}}^{\mathrm{o}}\right.$ in $\log \left(\mathrm{m}^{3} \mathrm{~mol}^{-1} \mathrm{~s}^{-1}\right), \Delta \mathrm{GAV}_{E_{\mathrm{a}}}^{\mathrm{o}}$ in $\left.\mathrm{kJ} \mathrm{mol}^{-1}\right)$

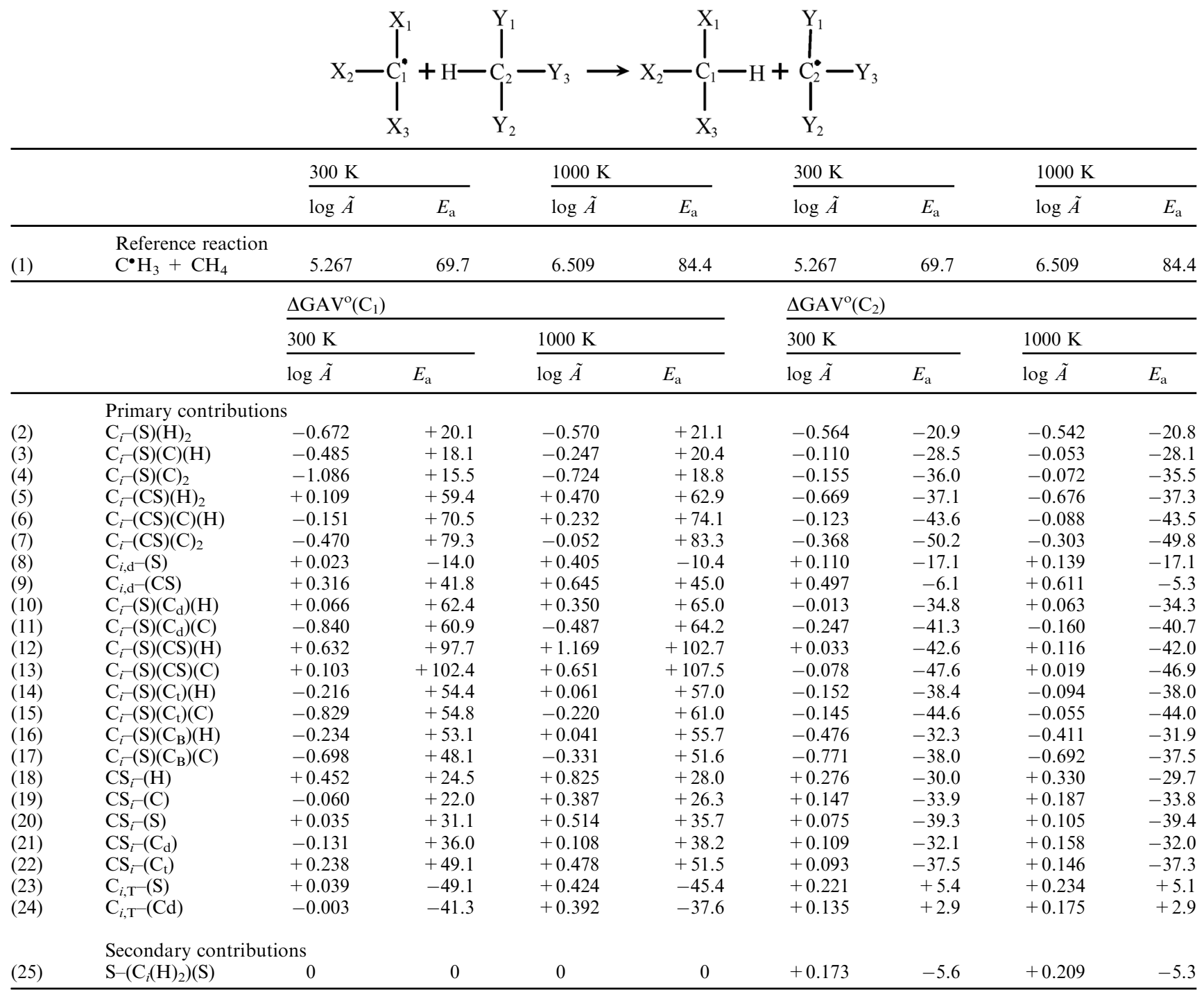
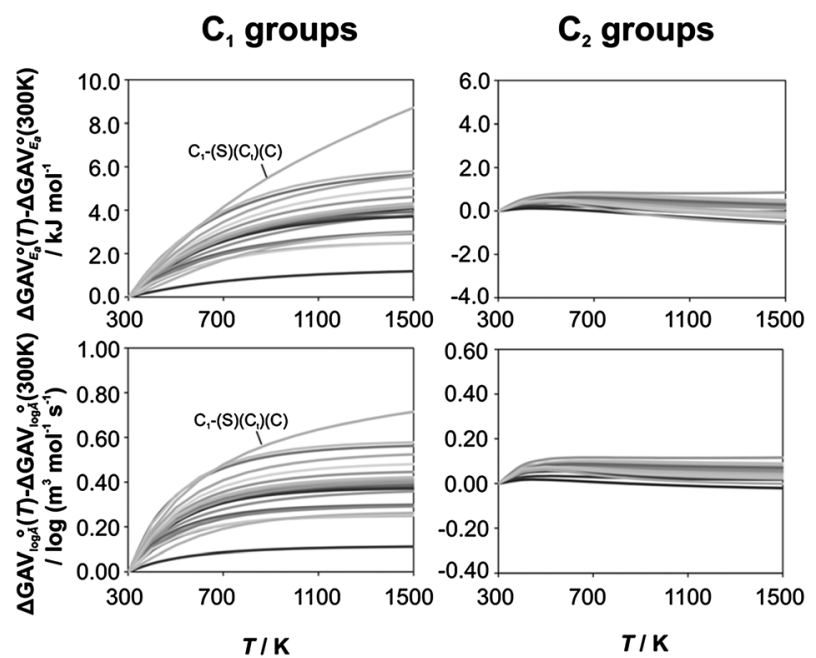

Fig. 6 Temperature dependence of the $\Delta \mathrm{GAV}^{\mathrm{o}} \mathrm{s}$ presented in Table 4.
$\mathrm{HC} \equiv \mathrm{CC}^{\bullet}(\mathrm{SH}) \mathrm{CH}_{3}$. The maximum error in the rate coefficient made by using the $\Delta \mathrm{GAV}^{\circ}(300 \mathrm{~K}) \mathrm{s}$ at different temperatures (up to $1500 \mathrm{~K}$ ) amounts to a factor of 3 . The limited temperature dependence illustrates that the $\Delta \mathrm{GAV}^{\mathrm{o}} \mathrm{s}$ can be used over a broad temperature range without a significant loss of accuracy.

3.3.2 The influence of secondary contributions and non-nearestneighbor interactions. An elaborate study of the effect of secondary contributions and NNIs can be found in Table 2 . In this table standard reaction enthalpies, single-event standard reaction entropies $\Delta_{\mathrm{r}} \tilde{S}^{\mathrm{o}}$ and Arrhenius parameters at $300 \mathrm{~K}$ are presented for 21 hydrogen abstraction reactions. Each reaction presented in Table 2 involves the hydrogen abstraction by a carbon-centered radical from a carbon atom having a neighboring sulfur atom, as illustrated by the reaction scheme presented at the top of this table. The 21 reactions are divided into six subsets according to the primary groups involved. Hydrogen abstractions within a subset of reactions have identical $C_{1}$ and $C_{2}$ groups but differ among each other by the $\mathrm{Y}$ and $\mathrm{Z}$ ligands (see the 
reaction scheme at the top of Table 2). The influence of the $\mathrm{Y}$ ligands can be evaluated by comparing the Arrhenius parameters obtained for reactions (25)-(30) with reactions (3) and (8). The effect of different $Z$ ligands is studied using reactions (31)-(41). The effect of secondary contributions and NNIs on the Arrhenius parameters can be quantified by studying the differences between the Arrhenius parameters for two reactions having identical $\mathrm{C}_{1}$ and $\mathrm{C}_{2}$ groups. Besides the influence of secondary contributions and NNIs on $E_{\mathrm{a}}$ and $\log \tilde{A}$, also deviations of the tunneling coefficient, reaction enthalpy, $\Delta_{\mathrm{r}} \tilde{S}^{\mathrm{o}}$ and rate coefficient $\tilde{k}$ were studied. The results of this study are shown in Table 5.

From Table 5 it can be seen that similar tunneling coefficients are obtained for reactions having the same $\mathrm{C}_{1}$ and $\mathrm{C}_{2}$ groups. Maximum deviations of the tunneling coefficients are limited to a factor of 1.25 . Also for $\Delta_{\mathrm{r}} \tilde{S}^{\mathrm{o}}$ and $\Delta_{\mathrm{r}} H^{\mathrm{o}}$ the differences between reactions having the same $\mathrm{C}_{1}$ and $\mathrm{C}_{2}$ groups are limited. The average deviations amount to $-0.4 \mathrm{~kJ} \mathrm{~mol}^{-1}$ and $-1.7 \mathrm{~J} \mathrm{~mol}^{-1} \mathrm{~K}^{-1}$ for $\Delta_{\mathrm{r}} H^{\mathrm{o}}$ and $\Delta_{\mathrm{r}} \tilde{S}^{\mathrm{o}}$, respectively. Maximum deviations are limited to $5 \mathrm{~kJ} \mathrm{~mol}^{-1}$ and $12 \mathrm{~J} \mathrm{~mol}^{-1} \mathrm{~K}^{-1}$. In general, good agreement is obtained between the Arrhenius parameters obtained within the same set of reactions, resulting in the fact that the $\tilde{k s}$ are reproduced on average within a factor of 2.4. The mean absolute deviations of the $\log \tilde{A}$ and activation energy amount to 0.217 and $2.1 \mathrm{~kJ} \mathrm{~mol}^{-1}$. This result shows that the influence of secondary contributions and NNIs on the studied hydrogen abstraction reactions is negligible. A truncated model including only primary contributions hence succeeds in accurately predicting Arrhenius parameters for hydrogen abstraction reactions involving organosulfur compounds.

The maximum deviation of the rate coefficients at $300 \mathrm{~K}$ amounts to a factor of 14.5 and is obtained for reaction (33) as compared to reaction (2). The large deviation is caused by an overestimation of the reaction barrier for the reverse reaction by $5.6 \mathrm{~kJ} \mathrm{~mol}^{-1}$, i.e. the hydrogen abstraction from methane by $\mathrm{HSSC}^{\bullet} \mathrm{H}_{2}$. This overestimation of the reaction barrier is caused by a mesomeric effect: the sulfur atom in the $\beta$-position of the radical site helps to stabilize the radical site. This effect will mainly influence the barrier for the endothermic reaction. A similar, but smaller effect is also observed for reactions (35)-(37). For reactions (35)-(37) the stabilizing effect of the sulfur atom in the $\beta$-position of the radical site is less pronounced, as the C-centered radical site is also stabilized by hyperconjugation. The additional stabilization of the S-atom in the $\beta$-position of the radical site is therefore smaller and deviations are limited to approximately $2 \mathrm{~kJ} \mathrm{~mol}^{-1}$. In general, additional ligands on the carbon atom bearing the radical site will reduce the influence of an $\mathrm{S}-\mathrm{S}$ bond adjacent to the radical site.
S-atom in the $\beta$-position of the radical site, i.e. $\mathrm{S}-\left(\mathrm{C}_{i}(\mathrm{H})_{2}\right)(\mathrm{S})$. The $\Delta \mathrm{GAV}^{\mathrm{o}} \mathrm{s}$ corresponding to this secondary contribution can be found at the bottom of Table 6 . The data presented in Table 5 for reaction (33) show that for the forward reaction the influence on $\log \tilde{A}$ and $E_{\mathrm{a}}$ is limited to 0.027 and $1.2 \mathrm{~kJ} \mathrm{~mol}^{-1}$, respectively. Therefore the $\Delta \mathrm{GAV}^{\mathrm{O}}\left(\mathrm{S}-\left(\mathrm{C}_{i}(\mathrm{H})_{2}\right)(\mathrm{S})\right)$ for the forward reaction can be set equal to 0 . The contributions of the $\mathrm{S}-\left(\mathrm{C}_{i}(\mathrm{H})_{2}\right)(\mathrm{S})$ group to the activation energy and $\log \tilde{A}$ for the reverse reaction amount to $-5.6 \mathrm{~kJ} \mathrm{~mol}^{-1}$ and +0.173 at $300 \mathrm{~K}$.

The data presented in Table 5 hence illustrate that secondary effects and NNIs have a limited influence on the reaction kinetics of hydrogen abstraction reactions. For all reactions studied, the maximum deviations of $\log \tilde{A}$ and $E_{\mathrm{a}}$ are limited to 0.67 and $6 \mathrm{~kJ} \mathrm{~mol}^{-1}$, respectively. This result is in agreement with the observations of Saeys et al. ${ }^{24}$ on the effect of secondary contributions and NNIs on the activation energies for radical addition reactions.

3.3.3 Resonance corrections. As explained in the methodology section, the resonance corrections account for stabilizing interactions in the transition state due to the simultaneous presence of groups on $\mathrm{C}_{1}$ and $\mathrm{C}_{2}$ and that cannot be included in the group-centered $\Delta \mathrm{GAV}^{\mathrm{o}} \mathrm{s}$. In Table 3 Arrhenius parameters and rate coefficients were presented for 32 reactions for which stabilizing cross-interactions in the transition state are expected. The influence of those cross-interactions on the Arrhenius parameters can be quantified by comparing the $a b$ initio calculated data with the GA modeled parameters using only the $\Delta \mathrm{GAV}^{\mathrm{o}} \mathrm{s}$ presented in Table 4 .

$$
\begin{gathered}
\Delta E_{\mathrm{res}}^{\mathrm{o}}=E_{\mathrm{a}}(T)-\left(E_{\mathrm{a}, \mathrm{ref}}(T)+\sum_{i=1}^{2} \Delta \mathrm{GAV}_{E_{\mathrm{a}}}^{\mathrm{o}}\left(\mathrm{C}_{i}\right)\right) \\
\Delta \log \tilde{A}_{\mathrm{res}}^{\mathrm{o}}=\log \tilde{A}(T)-\left(\log \tilde{A}_{\mathrm{ref}}(T)+\sum_{i=1}^{2} \Delta \mathrm{GAV}_{\log \tilde{A}}^{\mathrm{o}}\left(\mathrm{C}_{i}\right)\right)
\end{gathered}
$$

For example, the Arrhenius parameters for the hydrogen abstraction reaction $\mathrm{CH}_{3} \mathrm{SH}+\mathrm{CH}_{3} \mathrm{C}^{\bullet} \mathrm{HCH}_{3} \rightarrow \mathrm{C}_{2}^{\bullet} \mathrm{HSH}+$ $\mathrm{C}_{3} \mathrm{H}_{8}$ can be estimated from the data presented in Table 4 and ref. 26. The two primary groups involved in this reaction are the $\mathrm{C}_{1}-(\mathrm{C})_{2}(\mathrm{H})$ and $\mathrm{C}_{2}-(\mathrm{S})(\mathrm{H})_{2}$ groups. The GA estimated activation energy at $300 \mathrm{~K}$ hence amounts to $69.7+6.5-$ $20.9=55.3 \mathrm{~kJ} \mathrm{~mol}^{-1}$. This is $5 \mathrm{~kJ} \mathrm{~mol}^{-1}$ higher than the calculated value which amounts to $50.3 \mathrm{~kJ} \mathrm{~mol}^{-1}$ (reaction (58)). This deviation between calculated and GA estimated activation energy is caused by resonance stabilization. For the transition state, the following resonance structures represent the electron delocalization:

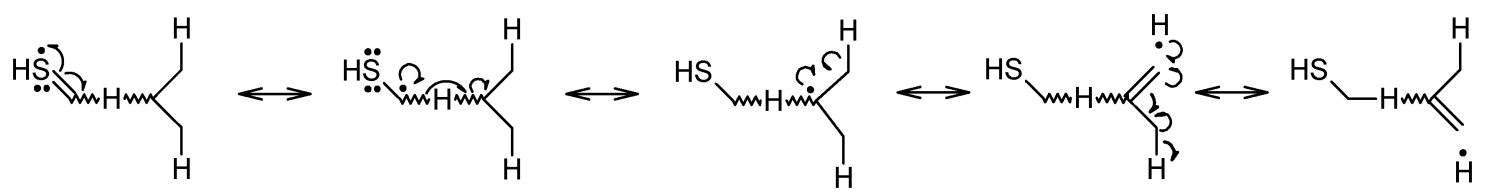

To extend the applicability of the GA scheme to abstraction reactions involving $\mathrm{C}^{\bullet} \mathrm{H}_{2} \mathrm{SSR}$ type of radicals, one secondary $\triangle \mathrm{GAV}^{\mathrm{o}}$ can be introduced accounting for the influence of an

These resonance structures describe the interaction of one of the lone electron pairs of the sulfur atom and two hyperconjugating $\mathrm{C}-\mathrm{H}$ bonds with the partially filled orbital. As illustrated in Fig. S7 
Table 5 Effect of secondary contributions and non-nearest-neighbor interactions on the tunneling coefficients $\kappa$, standard reaction enthalpies $\Delta_{\mathrm{r}} H^{\mathrm{o}}\left(\mathrm{kJ} \mathrm{mol}{ }^{-1}\right)$, single-event standard reaction entropies $\Delta_{\mathrm{r}} \tilde{S}^{\mathrm{o}}\left(\mathrm{J} \mathrm{mol}^{-1} \mathrm{~K}^{-1}\right)$, single-event pre-exponential factors $\log \tilde{A}\left(\log \left(\mathrm{m}^{3} \mathrm{~mol}^{-1} \mathrm{~s}^{-1}\right)\right)$, activation energies $E_{\mathrm{a}}\left(\mathrm{kJ} \mathrm{mol}^{-1}\right)$ and single-event rate coefficients $\tilde{k}\left(\mathrm{~m}^{3} \mathrm{~mol}^{-1} \mathrm{~s}^{-1}\right)$ at $300 \mathrm{~K}$ for the reactions presented in Table 2 . The reported values are the deviations between the calculated data for a target reaction and the corresponding data obtained for the smallest possible reaction having the same $C_{1}$ and $C_{2}$ groups (= training reaction, subscript $t$ ). The training reactions are indicated by -

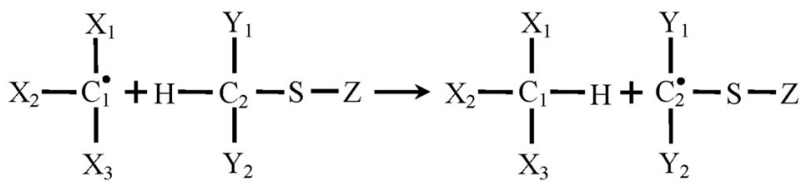

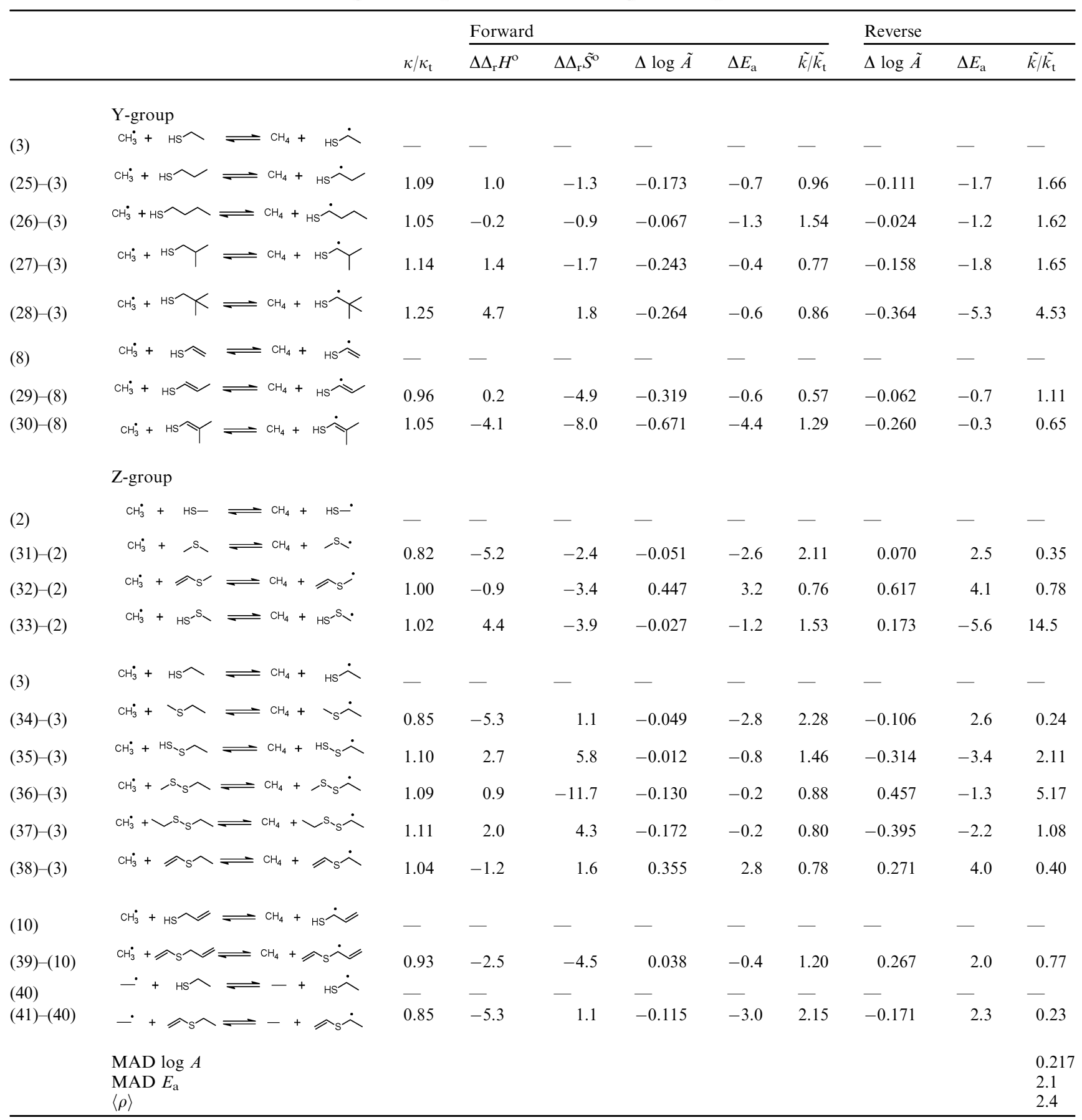

of the ESI $\dagger$, the spin density is delocalized on the sulfur atom and on the hydrogen atoms of the hyperconjugating $\mathrm{C}-\mathrm{H}$ bonds.
The effect of transition state resonance on both Arrhenius parameters for the reactions in Table 3 is presented in Table 6 . The reactions are grouped according to the different types of 
cross-interactions introduced in Section 2.2. Table 6 illustrates that, on average, resonance stabilization lowers the activation energies and pre-exponential factors by $15 \mathrm{~kJ} \mathrm{~mol}^{-1}$ and 0.319 . Similar deviations of the Arrhenius parameters are observed for reactions (42), (46) and (49), and, hence, one single

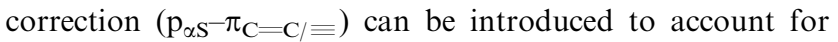
the cross-interaction of an $\alpha$-sulfur atom on $\mathrm{C}_{1}$ with a vinyl, ethynyl or phenyl ligand on $\mathrm{C}_{2}$. The smallest effects are obtained for reactions (58) and (59), whose transition states are stabilized by the $\mathrm{p}_{\alpha \mathrm{S}}-\sigma_{\beta \mathrm{C}-\mathrm{H}}$ cross-interaction of an $\alpha$-sulfur atom and hyperconjugating $\mathrm{C}-\mathrm{H}$ bonds. From the data obtained for reactions (58) and (59) and reactions (54)-(57), it can be seen that $\left|\Delta E_{\mathrm{a} \text {,res }}^{\mathrm{o}}\right|$ increases with an increasing number of methyl ligands. This increase amounts to approximately $2 \mathrm{~kJ} \mathrm{~mol}^{-1}$ for each additional methyl ligand. The largest effect on the activation energy amounts up to $34 \mathrm{~kJ} \mathrm{~mol}^{-1}$ and is obtained for reaction (68), i.e. the hydrogen abstraction of propanethial $\left(\mathrm{CH}_{3} \mathrm{CH}_{2} \mathrm{C}(=\mathrm{S}) \mathrm{H}\right)$ by the 1-thioxopropan-2-yl radical $\left(\mathrm{CH}_{3} \mathrm{C}^{\bullet} \mathrm{HC}(=\mathrm{S}) \mathrm{H}\right)$. The transition state of this reaction is stabilized both by the $\pi_{\mathrm{C}}=\mathrm{S}-\pi_{\mathrm{C}}=\mathrm{S}$ cross-interaction of two thiocarbonyl groups and by the $\pi_{\mathrm{C}=\mathrm{S}}-\sigma_{\beta \mathrm{C}-\mathrm{H}}$ cross-interaction of an adjacent thiocarbonyl group on the $\mathrm{C}_{1}$ atom with a $\beta \mathrm{C}-\mathrm{H}$ bond on the $\mathrm{C}_{2}$ atom. The data in Table 6 clearly show that resonance stabilization also influences the pre-exponential factors. Due to the occurrence of resonance in the transition state, the relative motion of the two reactants in the transition state is hampered, leading to lower pre-exponential factors. In analogy with the activation energy, correction factors are therefore presented to model $\log \tilde{A}$.

From a least squares regression of the 32 Arrhenius parameters presented in Table 3 , the 8 supplementary corrections required to account for cross-interactions in the transition state were derived. The results of this regression are presented in Table 7. The values for corrections $\pi_{\mathrm{C}=\mathrm{C}}-\pi_{\mathrm{C}}=\mathrm{C} / \equiv$,

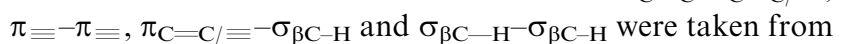
previous work. ${ }^{26}$ The largest stabilizing effects are obtained for the cross-interaction of a thiocarbonyl group with another $\pi$-conjugating system (see Fig. S1-S3 of the ESI $\dagger$ ). Activation energies can lower more than $20 \mathrm{~kJ} \mathrm{~mol}^{-1}$ due to the crossinteraction of a thiocarbonyl group on $\mathrm{C}_{1}$ and $\mathrm{C}_{2}$. Also on $\log \tilde{A}$ an important influence is observed. Pre-exponential factors can decrease up to a factor of 3 due to the simultaneous presence of a thiocarbonyl group on $\mathrm{C}_{1}$ and $\mathrm{C}_{2}$. The smallest correction factors are those describing the cross-interaction of a hyperconjugating $\mathrm{C}-\mathrm{H}$ bond with an $\alpha$-sulfur atom ( $\left.\mathrm{p}_{\alpha \mathrm{S}}-\sigma_{\beta \mathrm{C}-\mathrm{H}}\right)$ or a thiocarbonyl group $\left(\pi_{\mathrm{C}=\mathrm{S}}-\sigma_{\beta \mathrm{C}-\mathrm{H}}\right)$. In particular, the contribution of $\mathrm{p}_{\alpha \mathrm{S}}-\sigma_{\beta \mathrm{C}-\mathrm{H}}$ to $\log \tilde{A}$ is close to 0 and can be neglected. Its contribution to the activation energy amounts to $2 \mathrm{~kJ} \mathrm{~mol}^{-1}$ per interaction and can hence still be important, especially in cases where multiple corrections are needed to describe the occurring resonance. The data in Table 7 further illustrate that the correction factors are almost temperature independent. The deviations between the corrections obtained at $300 \mathrm{~K}$ and $1000 \mathrm{~K}$ amount to at most $0.6 \mathrm{~kJ} \mathrm{~mol}^{-1}$ and 0.07 for $E_{\mathrm{a}}$ and $\log \tilde{A}$, respectively.

In Table 6 it is shown that by using the corrections presented in Table 7, the activation energies and pre-exponential factors can be reproduced within $0.9 \mathrm{~kJ} \mathrm{~mol}^{-1}$ and 0.099 , respectively. The application of the resonance correction method is illustrated for one reaction, i.e. the hydrogen abstraction reaction by the propargyl radical from 2-propene-1-thiol (reaction (53)): $\mathrm{HC} \equiv \mathrm{C}-\mathrm{CH}^{\bullet}{ }_{2}+\mathrm{H}_{2} \mathrm{C}=\mathrm{CHCH}_{2} \mathrm{SH} \rightarrow \mathrm{HC} \equiv \mathrm{C}-\mathrm{CH}_{3}+$ $\mathrm{H}_{2} \mathrm{C}=\mathrm{CHC}{ }^{\bullet} \mathrm{HSH}$. The transition state of this reaction is presented in Fig. 7. In this figure it can be seen that the transition state is stabilized by the cross-interaction of (a) an ethynyl ligand on $C_{1}$ with an $\alpha$-S atom on $C_{2}$ and (b) an ethynyl ligand on $\mathrm{C}_{1}$ with an ethenyl ligand on $\mathrm{C}_{2}$. Using the presented group additivity model the activation energy and pre-exponential factor of reaction (53) are hence calculated as:

$$
\begin{aligned}
& E_{\mathrm{a}}(300 \mathrm{~K})=E_{\mathrm{a}, \text { ref }}(300 \mathrm{~K})+\Delta \mathrm{GAV}_{E_{\mathrm{a}}}^{\mathrm{o}}\left(\mathrm{C}_{1}-\left(\mathrm{C}_{\mathrm{t}}\right)(\mathrm{H})_{2}\right) \\
& +\Delta \mathrm{GAV}_{E_{\mathrm{a}}}^{\mathrm{o}}\left(\mathrm{C}_{2}-(\mathrm{S})\left(\mathrm{C}_{\mathrm{d}}\right)(\mathrm{H})\right)
\end{aligned}
$$

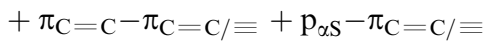

$$
\begin{aligned}
& =69.7+34.6-34.8-9.8-8.6 \\
& =51.1 \mathrm{~kJ} \mathrm{~mol}^{-1}
\end{aligned}
$$

$$
\begin{aligned}
& \log A(300 \mathrm{~K})=\log \tilde{A}_{\text {ref }}(300 \mathrm{~K})+\Delta \mathrm{GAV}_{\log \tilde{A}}^{\mathrm{o}}\left(\mathrm{C}_{1}-\left(\mathrm{C}_{\mathrm{t}}\right)(\mathrm{H})_{2}\right) \\
& +\Delta \mathrm{GAV}_{\log \tilde{A}}^{\mathrm{o}}\left(\mathrm{C}_{2}-(\mathrm{S})\left(\mathrm{C}_{\mathrm{d}}\right)(\mathrm{H})\right)
\end{aligned}
$$

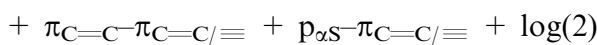

$$
\begin{aligned}
& =5.267-0.083-0.013-0.180-0.206 \\
& +0.301=5.086
\end{aligned}
$$

These values correspond well to the ab initio values of $55.0 \mathrm{~kJ} \mathrm{~mol}^{-1}$ and 5.086 for $E_{\mathrm{a}}$ and $\log A$, respectively.

3.3.4 Tunneling. By using eqn (9) the Eckart transmission coefficients for all hydrogen abstraction reactions presented in Tables 1-3 are reproduced on average within $10 \%$. The maximum deviation amounts to a factor of 2.7 and is obtained for reaction (62), i.e. the hydrogen abstraction by 3-methylbut-1en-3yl from ethanethial. In Fig. 8, a parity plot is shown in which the tunneling coefficients obtained with eqn (9) are presented versus those calculated using the Eckart scheme at $300 \mathrm{~K}$ and tunneling coefficients for all reactions are presented in Tables 1-3. At $300 \mathrm{~K}$ the Eckart tunneling coefficients are reproduced on average within a factor of 1.5 . $90 \%$ of the tunneling coefficients are reproduced within a factor of 2 . The agreement between modeled and calculated tunneling coefficients increases with increasing temperatures. At $1000 \mathrm{~K}$ the average deviation amounts to $3 \%$, with a maximum deviation of $10 \%$.

\subsection{Validation}

The presented $\Delta \mathrm{GAV}^{\mathrm{o}} \mathrm{s}$ are validated using a test set of $a b$ initio data for 30 reactions. Arrhenius parameters and rate coefficients for the test set in the temperature range $300-1500 \mathrm{~K}$ can be found in the ESI. $\dagger$ In Table 8 the deviations of the transmission coefficients, pre-exponential factor, activation energy and rate coefficients between the ab initio calculated and GA modeled values are presented at $300 \mathrm{~K}$. The MADs of $\log A$ and $E_{\mathrm{a}}$ amount to 0.132 and $2.5 \mathrm{~kJ} \mathrm{~mol}^{-1}$, respectively. The average deviation of the calculated rate coefficients amounts to a factor 2.4, indicating that the presented GA model reproduces the calculated rate 
Table 6 Effect of transition state cross-interaction on the activation energy and pre-exponential factor at $300 \mathrm{~K}$ for the reactions in Table 3 , according to eqn (13) and (14), and remaining deviations between calculated and GA modeled data after correcting for resonance stabilization

Resonance effect

$\Delta \log \tilde{A}_{\text {res }}$
$\Delta E_{\mathrm{a}, \mathrm{res}}$
Remaining deviation

$\Delta \log A$

$\begin{array}{rr}-0.044 & -0.9 \\ -0.113 & -0.4 \\ -0.126 & -0.3 \\ 0.322 & 0.1 \\ -0.012 & -2.0 \\ -0.145 & -2.2 \\ -0.266 & \\ 0.119 & -1.1 \\ 0.053 & 0.7 \\ 0.159 & 0.4 \\ 0.054 & 1.1 \\ 0.001 & 0.7 \\ & 3.9\end{array}$

1. Stmunn

(42)

$-\mathrm{SH}+\Downarrow \cdot \rightleftharpoons-_{\mathrm{SH}}+\Downarrow$

$-\mathrm{SH}+\dot{\sim} \rightleftharpoons \dot{-S H}_{\mathrm{SH}}+\underset{ }{\sim}$

$-0.250$

$-9.5$

$-11.0$

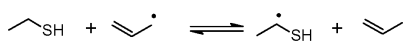

$-0.314$

$-0.394$

$-12.2$

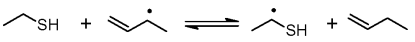

0.011

$-14.2$

$-\mathrm{SH}+\Longrightarrow-\mathrm{SH}+$

$-0.218$

$-10.6$

$-14.2$

$-16.5$

$-7.9$

$-10.3$

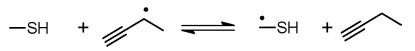

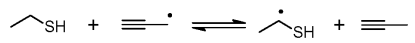

$-\mathrm{SH}+\dot{-}_{\mathrm{SH}} \rightleftharpoons \dot{-}_{\mathrm{SH}}+-\mathrm{SH}$

$-\mathrm{SH}+\dot{\hat{\Lambda}}_{\mathrm{SH}} \rightleftharpoons \dot{-}_{\mathrm{SH}}+\widehat{\widehat{S}}_{\mathrm{SH}}$

$-\mathrm{SH}+\dot{\iota}_{\mathrm{SH}} \rightleftharpoons \dot{-}_{\mathrm{SH}}+\grave{1}_{\mathrm{SH}}$

$\widehat{\widehat{S H}}+\dot{\hat{\curlywedge}}_{\mathrm{SH}} \rightleftharpoons \dot{\hat{\Upsilon}}_{\mathrm{SH}}+\widehat{\widehat{S H}}_{\mathrm{SH}}$

3.

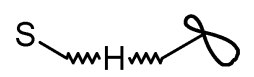

$-\mathrm{SH}+\dot{\hat{\gamma}} \rightleftharpoons \dot{-S H}_{\mathrm{SH}}+\widehat{\widehat{ }}$

$-\mathrm{SH}+\stackrel{\dot{\Lambda}}{ } \rightleftharpoons \dot{-S H}+\hat{\Lambda}$

4.

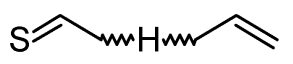

$s_{\Downarrow}+\Downarrow \dot{v}=s_{\Downarrow}+\vartheta$

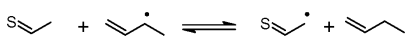

$s_{\vartheta}+\stackrel{\dot{\prime}}{\rightleftharpoons} s_{\vartheta}+\Downarrow$

5.

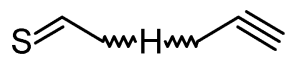

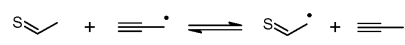

$s_{\Delta}+\dot{\gamma} \rightleftharpoons s_{\Delta}+\widehat{N}$

$s \triangleq+\stackrel{1}{\rightleftharpoons} s_{\Downarrow}+h$

6. $\mathrm{S}>\mathrm{\gamma mHm}$ - $\mathrm{S}$
$-0.058$

$-0.056$

$-0.411$

$-0.324$

$-0.355$

$-0.141$

$-0.365$

$-0.302$

$-0.638$

$-0.439$

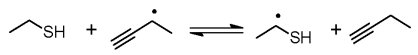

$\aleph_{\mathrm{SH}}+\equiv \cdot \dot{\sim}_{\mathrm{SH}}+\equiv$

2.

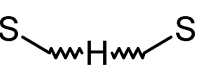

$-10.9$

$-13.6$

$-14.5$

\section{$-7.4$}

$-9.2$

$-10.1$

$-11.9$

$-5.0$

$-5.7$

$-19.2$

$-25.3$

$-28.3$

$-11.4$

$-16.8$

$-22.6$

$-22.6$

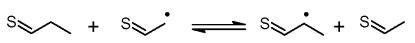

$-27.5$
0.043

$-0.3$

$-0.218$

$-0.4$

$-0.1$

1.0

$-0.9$

0.4

$-0.8$

$-1.1$

1.8

0.1

0.2

0.053

0.067 


\begin{tabular}{|c|c|c|c|c|c|}
\hline & & \multicolumn{2}{|c|}{ Resonance effect } & \multicolumn{2}{|c|}{ Remaining deviation } \\
\hline & & $\Delta \log \tilde{A}_{\text {res }}$ & $\Delta E_{\mathrm{a}, \mathrm{res}}$ & $\Delta \log A$ & $\Delta E_{\mathrm{a}}$ \\
\hline (68) & $s_{2}+s_{i}$ & -0.556 & -34.3 & 0.085 & -0.4 \\
\hline (69) & $\mathrm{s}_{2}+$ & -0.526 & -32.8 & 0.066 & 0.8 \\
\hline (71) & $\mathrm{s}_{\boldsymbol{\Omega}}+\dot{-} \mathrm{SH} \rightleftharpoons \mathrm{s}_{\boldsymbol{V}} \dot{\boldsymbol{\gamma}}+-\mathrm{SH}$ & -0.251 & -15.5 & 0.097 & -1.0 \\
\hline (72) & $s_{\nabla}+-\check{c} s_{\Delta}+-$ & -0.300 & -7.6 & -0.215 & -1.8 \\
\hline
\end{tabular}

coefficients accurately. The agreement between $a b$ initio and group additively estimated rate coefficients improves with increasing temperature and at $1000 \mathrm{~K}$ the rate coefficients are reproduced within a factor of 1.4. At $1000 \mathrm{~K}$ the largest deviation of the rate coefficients is limited to a factor of 3 .

Table 8 (third column) also shows the ratio of the estimated transmission coefficient (using eqn (9)) and calculated Eckart transmission coefficient $\left(\kappa / \kappa_{\mathrm{AI}}\right)$. It is seen that the transmission coefficients are reproduced accurately. The average deviation between the estimated and calculated $\kappa$ amounts to a factor of 1.4 at $300 \mathrm{~K}$. The maximum deviation is limited to a factor of 2.8 and is obtained for reaction (85). The data in Table 8 further show that good agreement is obtained between the $a b$ initio calculated kinetic parameters and the ones obtained by using the group additivity model. The largest deviation of $\log A$ is less than 0.5 while all activation energies are reproduced within $10 \mathrm{~kJ} \mathrm{~mol}^{-1}$. The largest deviations of $E_{\mathrm{a}}$ are obtained for hydrogen abstraction reactions by radicals that are stabilized by resonance. In these cases, special attention needs to be given to the thermochemistry of the reaction. For example, reaction (75) leads to the formation of a 3-sulfanyl-1-en-3-yl radical:

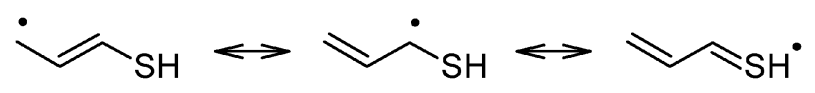

The $\Delta_{\mathrm{f}} H^{\mathrm{o}}$ of this radical is obtained by calculating the $\Delta_{\mathrm{f}} H^{\mathrm{o}} \mathrm{s}$ for the different resonance structures and then selecting the lowest value obtained. ${ }^{55}$ Using the GAVs presented in literature, ${ }^{55}$ the lowest $\Delta_{\mathrm{f}} H^{\mathrm{o}}$ is obtained for $\mathrm{CH}_{2}=\mathrm{CHC}{ }^{\bullet} \mathrm{HSH}$ which is $11.9 \mathrm{~kJ} \mathrm{~mol}^{-1}$ lower than the one obtained for $\mathrm{C}^{\bullet} \mathrm{H}_{2} \mathrm{CH}=\mathrm{CHSH}$. The $\Delta \operatorname{GAV}^{\mathrm{o}}\left(\mathrm{C}_{1}-\left(\mathrm{C}_{\mathrm{d}}\right)(\mathrm{H})_{2}\right)$ contribution used to estimate the activation energy for reaction (75) is obtained from a hydrogen abstraction by an allylic radical. It describes the enthalpy change between the $\mathrm{C}^{\bullet}-\left(\mathrm{C}_{\mathrm{d}}\right)(\mathrm{H})_{2}$ group in the reactant and the $\mathrm{C}-\left(\mathrm{C}_{\mathrm{d}}\right)(\mathrm{H})_{2}$ group in the transition state. Hence, $\Delta \mathrm{GAV}^{\mathrm{o}}\left(\mathrm{C}_{1}-\left(\mathrm{C}_{\mathrm{d}}\right)(\mathrm{H})_{2}\right)$ describes the enthalpy change going from $\mathrm{C}^{\bullet} \mathrm{H}_{2} \mathrm{CH}=\mathrm{CHSH}$ to the transition state. However, as the $\mathrm{C}^{\bullet} \mathrm{H}_{2} \mathrm{CH}=\mathrm{CHSH}$ resonance structure is not the most stable structure, an additional contribution needs to be added, accounting for the enthalpy difference between $\mathrm{CH}_{2}=\mathrm{CHC}^{\bullet} \mathrm{HSH}$ and $\mathrm{C}^{\bullet} \mathrm{H}_{2} \mathrm{CH}=\mathrm{CHSH}$. By simply using $\Delta \mathrm{GAV}^{\mathrm{O}}\left(\mathrm{C}_{1}-\left(\mathrm{C}_{\mathrm{d}}\right)(\mathrm{H})_{2}\right)$, the GA model underestimates the barrier for reaction $(75)$ by $9.5 \mathrm{~kJ} \mathrm{~mol}^{-1}$, resulting in an overestimation of the rate coefficient at $300 \mathrm{~K}$ by a factor of 150 . A correction for the enthalpy difference between the two resonance structures allows us to reproduce the barrier within $2.4 \mathrm{~kJ} \mathrm{~mol}^{-1}$ and the rate coefficients within a factor of 1.5 (see bracketed values in Table 8 for reaction (75)). Problems of this nature can be avoided by enforcing thermodynamic consistency in the GA model. In this case, the Arrhenius parameters for the exothermic reaction are estimated using the GA scheme, while those for the endothermic reactions are subsequently obtained from thermodynamic consistency.

The reactions presented in Table 8 can be divided into five groups. The first group of reactions (reactions (74)-(76)) are hydrogen abstraction reactions having a sulfur atom in the $\beta$ - or $\gamma$-position of the reactive center. For these three reactions the $\Delta \mathrm{GAV}^{\mathrm{o}}$ s derived for hydrocarbons by Sabbe et al. ${ }^{26}$ can be used. From Table 8 it is seen that using these $\Delta G^{\circ} V^{\circ}$ s the rate coefficients can be reproduced accurately, provided that thermodynamic consistency is enforced on reaction (75). The second group of reactions are hydrogen abstraction reactions by ethyl (reactions (40) and (77)-(80)). For these five reactions the GA model succeeds in reproducing all the rate coefficients within a factor of 4 . The maximum deviations of $\log A$ and $E_{\mathrm{a}}$ are small and are restricted to 0.3 and $3 \mathrm{~kJ} \mathrm{~mol}^{-1}$, respectively. For reactions (81)-(84), i.e. hydrogen abstraction reactions from dimethyl disulfide, larger deviations between calculated and GA data are observed. The barriers are on average reproduced within $2 \mathrm{~kJ} \mathrm{~mol}^{-1}$, resulting in rate coefficients which are reproduced within a factor of 1.3 to 2.5 . In case no additional correction for secondary effects in methyl disulfides was introduced, the reverse barriers would have been systematically overestimated by on average $5 \mathrm{~kJ} \mathrm{~mol}^{-1}$ leading to an underestimation of the rate coefficients for the reverse reactions by almost a factor of 10 at $300 \mathrm{~K}$. The fourth group of reactions, i.e. reactions (85)-(91), are hydrogen abstraction 
Table 7 Correction factor to account for additional resonance and hyperconjugative stabilization in the transition state at 300 , 600 and $1000 \mathrm{~K}$ $\left(E_{\mathrm{a}}\right.$ in $\left.\mathrm{kJ} \mathrm{mol}^{-1}\right)$. Italic values were taken from the work of Sabbe et al. ${ }^{26}$

\begin{tabular}{|c|c|c|c|c|c|c|c|c|c|c|}
\hline & \multirow[b]{2}{*}{ Correction } & \multirow[b]{2}{*}{ Corresponding structure } & \multicolumn{2}{|l|}{$300 \mathrm{~K}$} & \multicolumn{2}{|l|}{$600 \mathrm{~K}$} & \multicolumn{2}{|l|}{$1000 \mathrm{~K}$} & \multicolumn{2}{|l|}{ Average } \\
\hline & & & $\log \tilde{A}$ & $E_{\mathrm{a}}$ & $\log \tilde{A}$ & $E_{\mathrm{a}}$ & $\log \tilde{A}$ & $E_{\mathrm{a}}$ & $\log \tilde{A}$ & $E_{\mathrm{a}}$ \\
\hline (1) & $\pi_{\mathrm{C}}=\mathrm{C}-\pi_{\mathrm{C}}=\mathrm{C} / \equiv$ & & -0.180 & -9.8 & -0.202 & -10.0 & -0.212 & -10.1 & -0.198 & -10.0 \\
\hline (2) & $\pi \equiv-\pi \equiv$ & & -0.067 & -6.2 & -0.003 & -5.7 & 0.008 & -5.5 & -0.021 & -5.8 \\
\hline (3) & 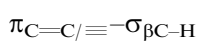 & & -0.061 & -3.4 & -0.052 & -3.3 & -0.053 & -3.4 & -0.055 & -3.4 \\
\hline (4) & $\sigma_{\beta C-H^{-}}-\sigma_{\beta C-H}$ & & -0.049 & -0.3 & -0.050 & -0.3 & -0.051 & -0.3 & -0.050 & -0.3 \\
\hline (5) & $\mathrm{p}_{\alpha \mathrm{S}}-\pi_{\mathrm{C}}=\mathrm{C} / \equiv$ & & -0.206 & -8.6 & -0.207 & -8.6 & -0.217 & -8.7 & -0.210 & -8.6 \\
\hline (6) & $\mathrm{p}_{\alpha \mathrm{S}}-\mathrm{p}_{\alpha \mathrm{S}}$ & & -0.366 & -7.1 & -0.299 & -6.6 & -0.293 & -6.5 & -0.319 & -6.7 \\
\hline (7) & $\mathrm{p}_{\alpha \mathrm{S}}-\sigma_{\beta \mathrm{C}-\mathrm{H}}$ & & 0.005 & -2.0 & 0.006 & -2.0 & 0.005 & -2.0 & 0.005 & -2.0 \\
\hline (8) & $\pi_{\mathrm{C}=\mathrm{S}}-\pi_{\mathrm{C}=\mathrm{C}}$ & & -0.278 & -18.4 & -0.292 & -18.6 & -0.306 & -18.8 & -0.292 & -18.6 \\
\hline (9) & $\pi_{\mathrm{C}=\mathrm{S}}-\pi \equiv$ & & -0.184 & -11.1 & -0.181 & -11.1 & -0.188 & -11.2 & -0.184 & -11.1 \\
\hline (10) & $\pi_{\mathrm{C}=\mathrm{S}}-\pi_{\mathrm{C}=\mathrm{S}}$ & & -0.421 & -21.9 & -0.370 & -21.6 & -0.374 & -21.6 & -0.388 & -21.7 \\
\hline (11) & $\pi_{\mathrm{C}=\mathrm{S}}-\mathrm{p}_{\alpha \mathrm{S}}$ & & -0.352 & -12.5 & -0.400 & -12.9 & -0.417 & -13.1 & -0.390 & -12.8 \\
\hline (12) & $\pi_{\mathrm{C}}=\mathrm{S}-\sigma_{\beta \mathrm{C}-\mathrm{H}}$ & & -0.085 & -5.8 & -0.099 & -6.0 & -0.108 & -6.1 & -0.097 & -6.0 \\
\hline
\end{tabular}

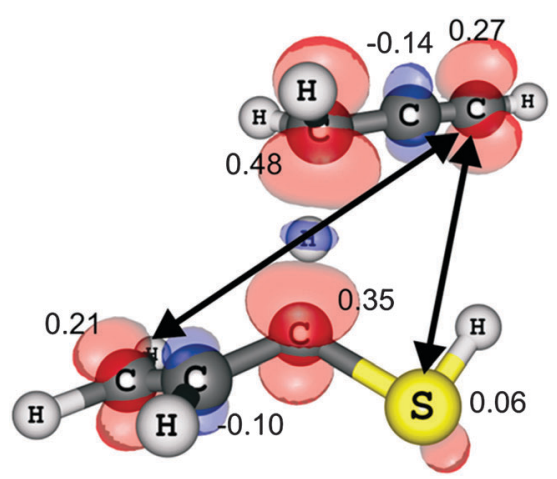

Fig. 7 Spin density plot and Mulliken atomic spin densities illustrating the resonance stabilization in the transition state for the hydrogen abstraction reaction by a propargyl radical from 2-propen-1-thiol (reaction (53)) (B3LYP/6-311G(2d,d,p), 0.006 isosurface).

reactions involving allylic and propargyl radicals. Five of the reactions studied in this group have transition state stabilization corrections ranging up to $15 \mathrm{~kJ} \mathrm{~mol}^{-1}$ and higher. It is seen that the GA model again succeeds in accurately reproducing the rate coefficients for these reactions; the rate coefficients are predicted within an average factor of 2.5, with a maximum of 5 . The last group pertains to hydrogen abstractions from methanethiol (reactions (92)-(102)). Once more the GA model succeeds in reproducing the calculated rate coefficients for all reactions in this group on average within a factor of 2.8 .

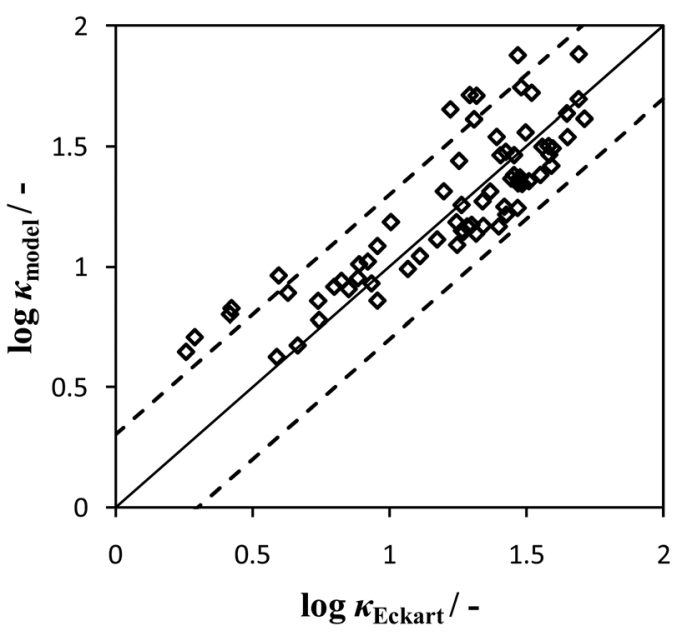

Fig. 8 Parity plot between Eckart tunneling coefficients at $300 \mathrm{~K}$ for the reactions presented in Tables $1-3$ and those estimated using eqn (9). The two dashed lines indicate deviations by a factor of 2 .

The use of the group additivity method is illustrated for two reactions, i.e. the abstraction of a hydrogen atom from methyl ethyl sulfide by ethyl (reaction (77)) and the hydrogen abstraction reaction from methanethiol by prop-2-en-1-thiol1-yl (reaction (97)). The Arrhenius parameters at $300 \mathrm{~K}$ for the reference reaction, i.e. hydrogen abstraction from methane by methyl, can be found in Table 4 and amount to 5.267 and $69.7 \mathrm{~kJ} \mathrm{~mol}^{-1}$, for, respectively, $\log \tilde{A}$ and $E_{\mathrm{a}}$. The primary 
Table 8 Comparison between $a b$ initio and GA kinetic parameters at $300 \mathrm{~K}$ for a set of 30 reactions. $\left(\Delta \log A=\log A_{\mathrm{GA}}-\log A_{\mathrm{AI}}\right.$ in $\log \left(\mathrm{m}^{3} \mathrm{~mol}^{-1} \mathrm{~s}^{-1}\right), \Delta E_{\mathrm{a}}=E_{\mathrm{a}, \mathrm{GA}}-E_{\mathrm{a}, \mathrm{AI}}$ in $\left.\mathrm{kJ} \mathrm{mol}^{-1}\right)$

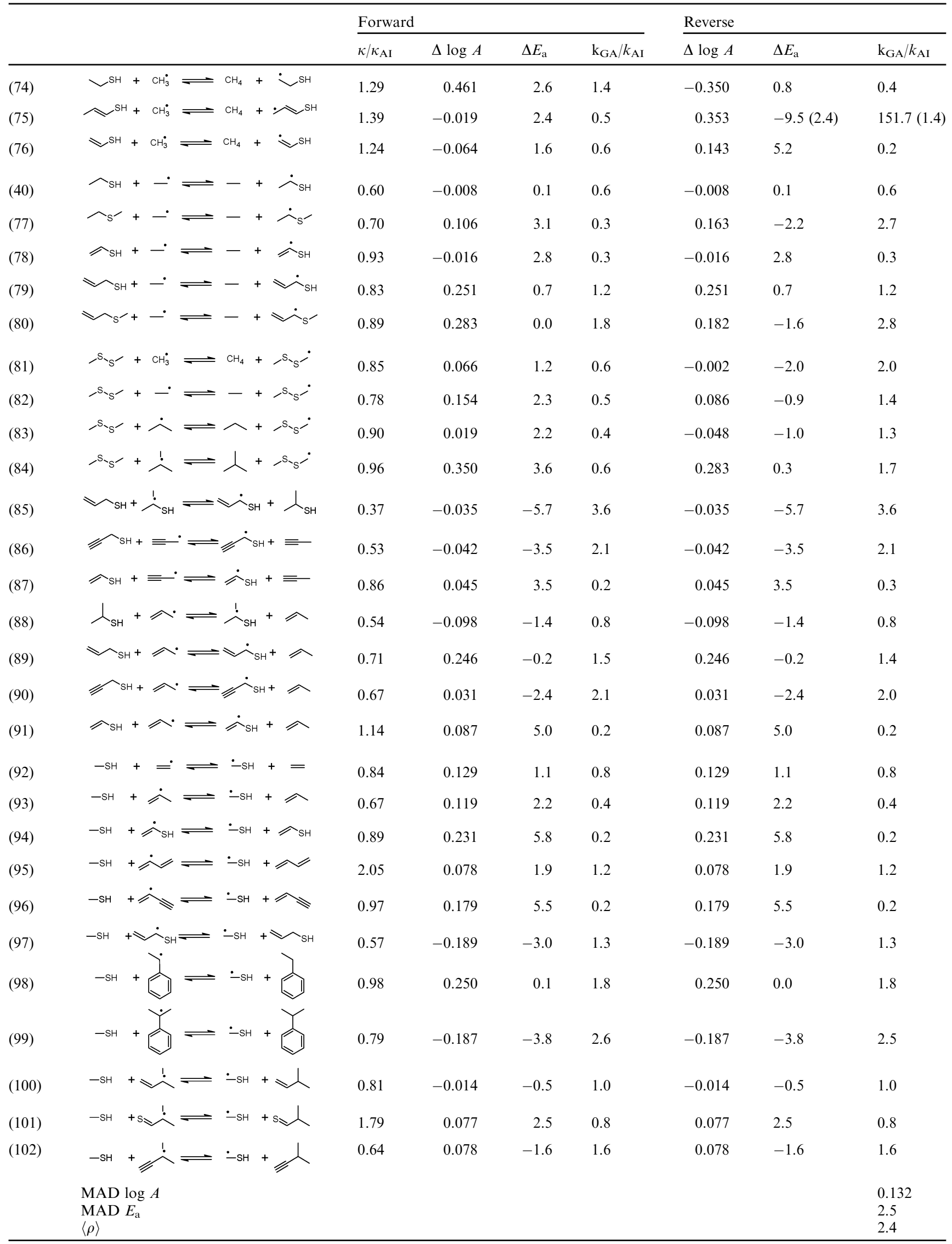


groups for reaction (77) are $\mathrm{C}_{1}-(\mathrm{C})(\mathrm{H})_{2}$ and $\mathrm{C}_{2}-(\mathrm{S})(\mathrm{C})(\mathrm{H})$. Their contributions to the activation energy amount to, respectively, +4.7 and $-28.5 \mathrm{~kJ} \mathrm{~mol}^{-1}$ while their contributions to $\log \tilde{A}$ are, respectively, -0.866 and -0.110 . The number of single events for this reaction amounts to four. This number originates from the two equivalent sides of the ethyl radical and from chirality in the transition state. The transition state of this reaction is stabilized by the cross-interaction of one hyperconjugating methyl group on the $\mathrm{C}_{1}$ group with one sulfur atom and one methyl group on the $\mathrm{C}_{2}$ group. The activation energy and pre-exponential factor are hence calculated as:

$$
\begin{aligned}
E_{\mathrm{a}}(300 \mathrm{~K})= & E_{\mathrm{a}, \mathrm{ref}}(300 \mathrm{~K})+\Delta \mathrm{GAV}_{E_{\mathrm{a}}}^{\mathrm{o}}\left(\mathrm{C}_{1}-(\mathrm{C})(\mathrm{H})_{2}\right) \\
& +\Delta \mathrm{GAV}_{E_{\mathrm{a}}}^{\mathrm{o}}\left(\mathrm{C}_{2}-(\mathrm{S})(\mathrm{C})(\mathrm{H})\right) \\
& +\sigma_{\beta \mathrm{C}-\mathrm{H}^{-}} \sigma_{\beta \mathrm{C}-\mathrm{H}}+\mathrm{p}_{\alpha \mathrm{S}}-\sigma_{\beta \mathrm{C}-\mathrm{H}} \\
= & 69.7+4.7-28.5-0.3-2.0 \\
= & 43.6 \mathrm{~kJ} \mathrm{~mol}^{-1}
\end{aligned}
$$

$$
\begin{aligned}
\log A(300 \mathrm{~K})= & \log \tilde{A}_{\mathrm{ref}}(300 \mathrm{~K})+\Delta \mathrm{GAV}_{\log \tilde{A}}^{\mathrm{o}}\left(\mathrm{C}_{1}-(\mathrm{C})(\mathrm{H})_{2}\right) \\
& +\Delta \mathrm{GAV}_{\log \tilde{A}}^{\mathrm{o}}\left(\mathrm{C}_{2}-(\mathrm{S})(\mathrm{C})(\mathrm{H})\right) \\
& +\sigma_{\beta \mathrm{C}-\mathrm{H}^{-}} \sigma_{\beta \mathrm{C}-\mathrm{H}}+\mathrm{p}_{\alpha \mathrm{S}^{-}} \sigma_{\beta \mathrm{C}-\mathrm{H}}+\log (4) \\
= & 5.267-0.866-0.110-0.049+0.005 \\
& +0.602=4.849
\end{aligned}
$$

In order to obtain reliable tunneling correction for this reaction, the exothermic reaction direction has to be identified. Using the $\Delta \mathrm{GAV}^{\mathrm{o}}$ s presented in Table 4 and the corrections in Table 7 the barrier for the reverse reaction is calculated as:

$$
\begin{aligned}
& E_{\mathrm{a}}(300 \mathrm{~K})=E_{\mathrm{a}, \text { ref }}(300 \mathrm{~K})+\Delta \mathrm{GAV}_{E_{\mathrm{a}}}^{\mathrm{o}}\left(\mathrm{C}_{1}-(\mathrm{S})(\mathrm{C})(\mathrm{H})\right) \\
& +\Delta \mathrm{GAV}_{E_{\mathrm{a}}}^{\mathrm{o}}\left(\mathrm{C}_{2}-(\mathrm{C})(\mathrm{H})_{2}\right) \\
& +\sigma_{\beta \mathrm{C}-\mathrm{H}}-\sigma_{\beta \mathrm{C}-\mathrm{H}}+\mathrm{p}_{\alpha \mathrm{S}}-\sigma_{\beta \mathrm{C}-\mathrm{H}} \\
& =69.7+18.1+5.4-0.3-2.0 \\
& =90.9 \mathrm{~kJ} \mathrm{~mol}^{-1}
\end{aligned}
$$

As this barrier is higher than the one obtained for the forward reaction, it is concluded that hydrogen abstraction from ethanethiol by ethyl is exothermic. Substitution of $E_{\mathrm{a}, \text { exo }}=$ $43.6 \mathrm{~kJ} \mathrm{~mol}^{-1}$ in eqn (9) yields a transmission coefficient of 17.7 at $300 \mathrm{~K}$, which corresponds within a factor of 2 to the calculated transmission coefficients of 25.1. The calculated $E_{\mathrm{a}}$ and $\log A$ amount to, respectively, $40.5 \mathrm{~kJ} \mathrm{~mol}^{-1}$ and 4.743 . The GA model hence succeeds in estimating the rate coefficient for this reaction within a factor of 4 .

The primary groups for reaction $(97)$ are $\mathrm{C}_{1}-(\mathrm{S})\left(\mathrm{C}_{\mathrm{d}}\right)(\mathrm{H})$ and $\mathrm{C}_{2}-(\mathrm{S})(\mathrm{H})_{2}$. Their contributions to the activation energy amount to, respectively, +62.4 and $-20.9 \mathrm{~kJ} \mathrm{~mol}^{-1}$ while their contributions to $\log \tilde{A}$ are, respectively, +0.066 and -0.564 . The transition state is stabilized by the cross-interaction of one $\alpha-S$ atom and one $\mathrm{C}=\mathrm{C}$ ligand on the $\mathrm{C}_{1}$ group with one $\alpha$-S atom on the $C_{2}$ group. The number of single events for this reaction amounts to six corresponding to the three equivalents of hydrogen atoms in methanethiol and chirality in the transition state. The activation energy and pre-exponential factor are hence calculated as:

$$
\begin{aligned}
& E_{\mathrm{a}}(300 \mathrm{~K})=E_{\mathrm{a}, \text { ref }}(300 \mathrm{~K})+\Delta \mathrm{GAV}_{E_{\mathrm{a}}}^{\mathrm{o}}\left(\mathrm{C}_{1}-(\mathrm{S})\left(\mathrm{C}_{\mathrm{d}}\right)(\mathrm{H})\right) \\
& +\Delta \mathrm{GAV}_{E_{\mathrm{a}}}^{\mathrm{o}}\left(\mathrm{C}_{2}-(\mathrm{S})(\mathrm{H})_{2}\right) \\
& +\mathrm{p}_{\alpha \mathrm{S}}-\pi_{\mathrm{C}}=\mathrm{C} / \equiv+\mathrm{p}_{\alpha \mathrm{S}}-\mathrm{p}_{\alpha \mathrm{S}} \\
& =69.7+62.4-20.9-8.6-7.1 \\
& =95.5 \mathrm{~kJ} \mathrm{~mol}^{-1}
\end{aligned}
$$

$$
\begin{aligned}
& \log A(300 \mathrm{~K})=\log \tilde{A}_{\mathrm{ref}}(300 \mathrm{~K})+\Delta \mathrm{GAV}_{\log \tilde{A}}^{\mathrm{o}}\left(\mathrm{C}_{1}-(\mathrm{S})\left(\mathrm{C}_{\mathrm{d}}\right)(\mathrm{H})\right) \\
& +\Delta \mathrm{GAV}_{\log \tilde{A}}^{\mathrm{o}}\left(\mathrm{C}_{2}-(\mathrm{S})(\mathrm{H})_{2}\right)
\end{aligned}
$$

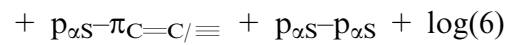

$$
\begin{aligned}
& =5.267+0.066-0.564-0.206-0.366 \\
& +0.778=4.975
\end{aligned}
$$

The activation energy for the reverse reaction amounts to:

$$
\begin{aligned}
& E_{\mathrm{a}}(300 \mathrm{~K})=E_{\mathrm{a}, \text { ref }}(300 \mathrm{~K})+\Delta \mathrm{GAV}_{E_{\mathrm{a}}}^{\mathrm{o}}\left(\mathrm{C}_{1}-(\mathrm{S})(\mathrm{H})_{2}\right) \\
& +\Delta \mathrm{GAV}_{E_{\mathrm{a}}}^{\mathrm{o}}\left(\mathrm{C}_{2}-(\mathrm{S})\left(\mathrm{C}_{\mathrm{d}}\right)(\mathrm{H})\right) \\
& +\mathrm{p}_{\alpha \mathrm{S}}-\pi_{\mathrm{C}}=\mathrm{C} / \equiv+\mathrm{p}_{\alpha \mathrm{S}}-\mathrm{p}_{\alpha \mathrm{S}} \\
& =69.7+20.1-34.8-8.6-7.1 \\
& =39.4 \mathrm{~kJ} \mathrm{~mol}^{-1}
\end{aligned}
$$

The reverse reaction is hence the exothermic reaction. Substitution of $E_{\mathrm{a} \text {,exo }}=39.4 \mathrm{~kJ}$ in eqn (9) yields a transmission coefficient of 13.7 at $300 \mathrm{~K}$. The calculated $E_{\mathrm{a}}$ and $\log A$ amount to, respectively, $98.5 \mathrm{~kJ} \mathrm{~mol}^{-1}$ and 5.165. The GA model succeeds in predicting the rate coefficient for this reaction within a factor of 1.3 .

In Fig. 9 the accuracy of the GA model is compared to other models such as the one proposed by Blowers and Masel (eqn (10)) and the intersecting parabolas model. The IP model departs from the following relationship between the activation energy and reaction enthalpy: ${ }^{16}$

$$
b=a\left(E_{\mathrm{a}}-\Delta_{\mathrm{r}} H^{\mathrm{o}}\right)^{1 / 2}-E_{\mathrm{a}}^{1 / 2}
$$

with $a$ and $b$ two fitting parameters which relate to the force constants of the broken and formed hydrogen bonds and the hydrogen atom displacement during abstraction. The parity diagram shows the estimated activation energy as a function of the $a b$ initio calculated activation energy for the 30 reactions presented in Table 6. It can be seen that the GA model outperforms the other models. As discussed above, the MAD between calculated and GA estimated activation energies amounts to approximately $3 \mathrm{~kJ} \mathrm{~mol}^{-1}$. The MADs obtained with the Blowers and Masel model and the intersecting parabolas model amount to $8-9 \mathrm{~kJ} \mathrm{~mol}^{-1}$. Large deviations are particularly obtained for reactions having resonance stabilized transition states. For example, both BEP type models overestimate the barriers for reaction (83) by $16 \mathrm{~kJ} \mathrm{~mol}^{-1}$. Besides the less accurate estimates for the activation energy, these BEP-type models do not give access to pre-exponential factors. 


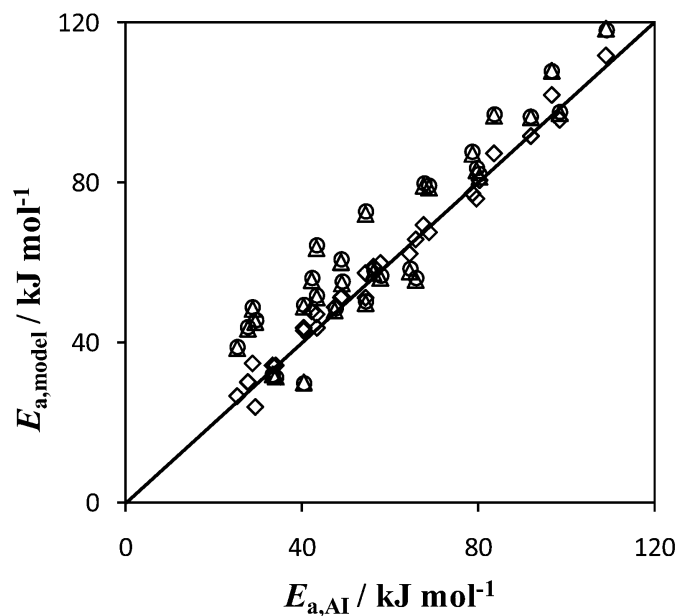

Fig. 9 Parity plot for the activation energies at $300 \mathrm{~K}$ calculated from CBS-QB3 rate coefficients and those obtained using the GA method presented in this work $(\diamond)$, the Blowers and Masel model with $w_{\mathrm{f}}+w_{\mathrm{b}}=800 \mathrm{~kJ} \mathrm{~mol}^{-1}$ and $V_{\mathrm{p}}=1114 \mathrm{~kJ} \mathrm{~mol}^{-1}(\triangle)$ and the intersecting parabolas model with $a=1$ and $b=16.3(\bigcirc)$.

\section{Conclusions}

In this work a group additivity model is presented that allows us to estimate the Arrhenius parameters and rate coefficients for hydrogen abstraction reactions from carbon atoms in sulfides and thiocarbonyl compounds in the temperature range $300-1500 \mathrm{~K}$. This work is an extension of previous work on modeling of the Arrhenius parameters for hydrogen abstractions involving hydrocarbons. ${ }^{26}$

In order to derive and validate group additivity values, high-pressure limit rate coefficients were calculated using the CBS-QB3 method for more than 100 reactions. The rate coefficients were corrected for 1-D hindered rotation about the transition state bond. Tunneling contributions are modeled explicitly using an equation that correlates the tunneling contributions to the temperature and activation energy for the exothermic reaction.

From a training set containing 24 reactions, $46 \Delta \mathrm{GAV}^{\mathrm{o}} \mathrm{s}$ were derived that can be used to model hydrogen abstraction reactions involving carbon atoms having a neighboring $\mathrm{S}$ or CS ligand. In general, the influence of secondary effects and NNIs on the Arrhenius parameters is limited. However, at low temperatures deviations of a few $\mathrm{kJ} \mathrm{mol}^{-1}$ of the activation energy can lead to deviations of the rate coefficients up to one order of magnitude. In order to enhance the applicability of the presented GA method, one secondary contribution was introduced to account for hydrogen abstractions involving methyl disulfides. Resonance stabilization in the transition states was studied for a set of 32 reactions. As resonance stabilization can decrease the activation energy to $30 \mathrm{~kJ} \mathrm{~mol}^{-1}$, 8 additional correction terms were introduced, which are able to describe this effect. The values for the 8 correction terms were obtained from a least squares regression. The introduction of corrections terms for transition state stabilization lowered the mean absolute deviation between ab initio and group additively estimated activation energies from 15.3 to $0.9 \mathrm{~kJ} \mathrm{~mol}^{-1}$, hence significantly improving the accuracy of the GA model.
The developed group additivity scheme was validated using a test set containing an additional 30 reactions. The group additivity scheme succeeds in reproducing the rate coefficients on average within a factor of 2.4 at $300 \mathrm{~K}$. The mean absolute deviations of the Arrhenius parameters amount to, respectively, $2.5 \mathrm{~kJ} \mathrm{~mol}^{-1}$ for $E_{\mathrm{a}}$ and 0.132 for $\log A$. The agreement between calculated and GA estimated data improves with increasing temperature. At $1000 \mathrm{~K}$ the rate coefficients are reproduced within an average factor of deviation of 1.4. It is hence concluded that the group additivity schemes, developed for elementary reactions between hydrocarbons, extrapolate successfully to compounds containing hetero-elements.

\section{Acknowledgements}

The authors acknowledge financial support from the Fund for Scientific Research Flanders (FWO), the 'Long Term Structural Methusalem Funding by the Flemish Government' and the Stevin Supercomputer Infrastructure at Ghent University, funded by Ghent University, the Hercules Foundation and the Flemish Government - Department EWI.

\section{References}

1 I. Barnes, J. Hjorth and N. Mihalopoulos, Chem. Rev., 2006, 106, 940-975.

2 S. Sorensen, H. FalbeHansen, M. Mangoni, J. Hjorth and N. R. Jensen, J. Atmos. Chem., 1996, 24, 299-315.

3 J. Kice, in Free Radicals, ed. J. K. Kochi, Wiley, New York, 1973, vol. II, pp. 711-740.

4 L. G. S. Shum and S. W. Benson, Int. J. Chem. Kinet., 1985, 17, 749-761.

5 G. Martin and N. Barroeta, J. Chem. Soc., Perkin Trans. 2, 1976, 1421-1424.

6 G. Martin and N. Barroeta, Int. J. Chem. Kinet., 1980, 12, 699-716.

7 G. Martin, A. Drayer, M. Ropero and M. E. Alonso, Int. J. Chem. Kinet., 1982, 14, 131-141.

8 S. Patai and Z. Rappoport, The Chemistry of sulphur-containing functional groups, Wiley, Chichester [England], New York, 1993.

9 X. Zheng, E. M. Fisher, F. C. Gouldin, L. Zhu and J. W. Bozzelli, Proc. Combust. Inst., 2009, 32, 469-476.

10 A. G. Vandeputte, M. F. Reyniers and G. B. Marin, J. Phys. Chem. A, 2010, 114, 10531-10549.

11 E. H. Braye, A. H. Sehon and B. D. B. Darwent, J. Am. Chem. Soc., 1955, 77, 5282-5285.

12 K. M. Van Geem, M. F. Reyniers, G. B. Marin, J. Song, W. H. Green and D. M. Matheu, AIChE J., 2006, 52, 718-730.

13 M. Bajus, Sulfur Rep., 1989, 9, 25-71.

14 M. G. Evans and J. C. Polanyi, Trans. Faraday Soc., 1936, 32 $1333-1360$.

15 J. C. Polanyi and W. H. Wong, J. Chem. Phys., 1969, 51, 1439-1450.

16 E. T. Denisov, Usp. Khim., 1997, 66, 953-971.

17 P. Blowers and R. Masel, AIChE J., 2000, 46, 2041-2052.

18 A. A. Zavitsas, J. Am. Chem. Soc., 1998, 120, 6578-6586.

19 X. L. Ma and H. H. Schobert, Ind. Eng. Chem. Res., 2003, 42, 1151-1161.

20 P. F. Su, L. C. Song, W. Wu, P. C. Hiberty and S. Shark, J. Am. Chem. Soc., 2004, 126, 13539-13549.

21 S. W. Benson, Thermochemical kinetics: methods for the estimation of thermochemical data and rate parameters, Wiley, New York, 1968.

22 P. A. Willems and G. F. Froment, Ind. Eng. Chem. Res., 1988, 27, 1959-1966.

23 P. A. Willems and G. F. Froment, Ind. Eng. Chem. Res., 1988, 27, 1966-1971.

24 M. Saeys, M. F. Reyniers, G. B. Marin, V. Van Speybroeck and M. Waroquier, AIChE J., 2004, 50, 426-444. 
25 M. Saeys, M. F. Reyniers, V. Van Speybroeck, M. Waroquier and G. B. Marin, ChemPhysChem, 2006, 7, 188-199.

26 M. K. Sabbe, A. G. Vandeputte, M. F. Reyniers, M. Waroquier and G. B. Marin, Phys. Chem. Chem. Phys., 2010, 12, 1278-1298.

27 R. Sumathi, H. H. Carstensen and W. H. Green, J. Phys. Chem. A, 2001, 105, 6910-6925.

28 R. Sumathi, H. H. Carstensen and W. H. Green, J. Phys. Chem. A, 2001, 105, 8969-8984.

29 T. N. Truong, W. T. Duncan and M. Tirtowidjojo, Phys. Chem. Chem. Phys., 1999, 1, 1061-1065.

30 N. Kungwan and T. N. Truong, J. Phys. Chem. A, 2005, 109, $7742-7750$.

31 L. K. Huynh, S. Panasewicz, A. Ratkiewicz and T. N. Truong, J. Phys. Chem. A, 2007, 111, 2156-2165.

32 A. Ratkiewicz and T. N. Truong, Int. J. Chem. Kinet., 2010, 42, 414-429.

33 A. Ratkiewicz, J. Bieniewska and T. N. Truong, Int. J. Chem. Kinet., 2011, 43, 78-98.

34 M. K. Sabbe, M. F. Reyniers, M. Waroquier and G. B. Marin, ChemPhysChem, 2010, 11, 195-210.

35 A. J. Adamczyk, M. F. Reyniers, G. B. Marin and L. J. Broadbelt, J. Phys. Chem. A, 2009, 113, 10933-10946.

36 A. J. Adamczyk, M. F. Reyniers, G. B. Marin and L. J. Broadbelt, Phys. Chem. Chem. Phys., 2010, 12, 12676-12696.

37 A. J. Adamczyk, M. F. Reyniers, G. B. Marin and L. J. Broadbelt, Theor. Chem. Acc., 2011, 128, 91-113.

38 H. H. Carstensen and A. M. Dean, Proc. Combust. Inst., 2005, 30, 995-1003.

39 H. H. Carstensen, A. M. Dean and O. Deutschmann, Proc. Combust. Inst., 2007, 31, 149-157.

40 A. G. Vandeputte, M. K. Sabbe, M. F. Reyniers, V. Van Speybroeck, M. Waroquier and G. B. Marin, J. Phys. Chem. A, 2007, 111, 11771-11786.

41 M. L. Coote, J. Phys. Chem. A, 2004, 108, 3865-3872.

42 J. J. Zheng, Y. Zhao and D. G. Truhlar, J. Phys. Chem. A, 2007, 111, 4632-4642.

43 J. J. Zheng, Y. Zhao and D. G. Truhlar, J. Chem. Theory Comput., 2007, 3, 569-582.

44 W. U. Eckart, Phys. Rev., 1930, 35.
45 J. A. Montgomery, M. J. Frisch, J. W. Ochterski and G. A. Petersson, J. Chem. Phys., 1999, 110, 2822-2827.

46 M. J. Frisch, G. W. Trucks, H. B. Schlegel, G. E. Scuseria, M. A. Robb, J. R. Cheeseman, J. A. Montgomery, Jr., T. Vreven, K. N. Kudin, J. C. Burant, J. M. Millam, S. S. Iyengar, J. Tomasi, V. Barone, B. Mennucci, M. Cossi, G. Scalmani, N. Rega, G. A. Petersson, H. Nakatsuji, M. Hada, M. Ehara, K. Toyota, R. Fukuda, J. Hasegawa, M. Ishida, T. Nakajima, Y. Honda, O. Kitao, H. Nakai, M. Klene, X. Li, J. E. Knox, H. P. Hratchian, J. B. Cross, V. Bakken, C. Adamo, J. Jaramillo, R. Gomperts, R. E. Stratmann, O. Yazyev, A. J. Austin, R. Cammi, C. Pomelli, J. W. Ochterski, P. Y. Ayala, K. Morokuma, G. A. Voth, P. Salvador, J. J. Dannenberg, V. G. Zakrzewski, S. Dapprich, A. D. Daniels, M. C. Strain, O. Farkas, D. K. Malick, A. D. Rabuck, K. Raghavachari, J. B. Foresman, J. V. Ortiz, Q. Cui, A. G. Baboul, S. Clifford, J. Cioslowski, B. B. Stefanov, G. Liu, A. Liashenko, P. Piskorz, I. Komaromi, R. L. Martin, D. J. Fox, T. Keith, M. A. Al-Laham, C. Y. Peng, A. Nanayakkara, M. Challacombe, P. M. W. Gill, B. Johnson, W. Chen, M. W. Wong, C. Gonzalez and J. A. Pople, Gaussian 03, Revision C.02, Wallingford, CT, 2004.

47 V. Van Speybroeck, P. Vansteenkiste, D. Van Neck and M. Waroquier, Chem. Phys. Lett., 2005, 402, 479-484.

48 J. Pfaendtner, X. Yu and L. J. Broadbelt, Theor. Chem. Acc., 2007, 118, 881-898.

49 M. K. Sabbe, M. F. Reyniers, V. Van Speybroeck, M. Waroquier and G. B. Marin, ChemPhysChem, 2008, 9, 124-140.

50 A. Fernandez-Ramos, B. A. Ellingson, R. Meana-Paneda, J. M. C. Marques and D. G. Truhlar, Theor. Chem. Acc., 2007, 118, 813-826.

51 S. R. D. NIST Chemistry webbook, June 2005. http://webbook. nist.gov/, 2005.

52 G. Ercolani, C. Piguet, M. Borkovec and J. Hamacek, J. Phys. Chem. B, 2007, 111, 12195-12203.

53 N. L. Arthur and M. S. Lee, Aust. J. Chem., 1976, 29, 1483-1492.

54 M. M. Ekwenchi, I. Safarik and O. P. Strausz, Can. J. Chem., 1981, 59, 3226-3231.

55 A. G. Vandeputte, M. K. Sabbe, M. F. Reyniers and G. B. Marin, Chem.-Eur. J., 2011, 17, 7656-7673. 